\title{
Ordered Recruitment of Dynactin to the Microtubule Plus-End is Required for Efficient Initiation of Retrograde Axonal Transport
}

\author{
Armen J. Moughamian, Gregory E. Osborn, Jacob E. Lazarus, Sandra Maday, and Erika L.F. Holzbaur \\ Department of Physiology, Perelman School of Medicine at the University of Pennsylvania, Philadelphia, Pennsylvania 19104-6085
}

\begin{abstract}
Long-range retrograde axonal transport in neurons is driven exclusively by the microtubule motor cytoplasmic dynein. The efficient initiation of dynein-mediated transport from the distal axon is critical for normal neuronal function, and neurodegenerative diseaseassociated mutations have been shown to specifically disrupt this process. Here, we examine the role of dynamic microtubules and microtubule plus-end binding proteins (+ TIPs) in the initiation of dynein-mediated retrograde axonal transport using live-cell imaging of cargo motility in primary mouse dorsal root ganglion neurons. We show that end-binding (EB)-positive dynamic microtubules are enriched in the distal axon. The +TIPs EB1, EB3, and cytoplasmic linker protein-170 (CLIP-170) interact with these dynamic microtubules, recruiting the dynein activator dynactin in an ordered pathway, leading to the initiation of retrograde transport by the motor dynein. Once transport has initiated, however, neither the EBs nor CLIP-170 are required to maintain transport flux along the mid-axon. In contrast, the + TIP Lis1 activates transport through a distinct mechanism and is required to maintain processive organelle transport along both the distal and mid-axon. Further, we show that the EB/CLIP-170/dynactin-dependent mechanism is required for the efficient initiation of transport from the distal axon for multiple distinct cargos, including mitochondria, Rab5-positive early endosomes, late endosomes/lysosomes, and TrkA-, TrkB-, and APP-positive organelles. Our observations indicate that there is an essential role for + TIPs in the regulation of retrograde transport initiation in the neuron.
\end{abstract}

\section{Introduction}

Cytoplasmic dynein is the primary microtubule motor for retrograde axonal transport (Perlson et al., 2010). Active organelle transport from the synapse to the cell soma is essential to maintaining neuronal homeostasis; mutations that disrupt dyneinmediated axonal transport result in neurodegenerative disease (Perlson et al., 2010). Dynein function is highly regulated; activator proteins or adaptors including dynactin and Lis1 bind to dynein to regulate the activity of the motor (Kardon and Vale, 2009; Kardon et al., 2009).

Dynactin is a multisubunit complex that is necessary for most dynein-mediated functions, including retrograde axonal transport (Schroer, 2004). Dynactin enhances the processivity of dynein (King and Schroer, 2000; Ross et al., 2006) and also mediates cargo interactions (Holleran et al., 1996; Watson et al., 2005;

\footnotetext{
Received March 1, 2013; revised June 6, 2013; accepted June 11, 2013.

Author contributions: A.J.M., G.E.O., J.E.L., S.M., and E.L.F.H. designed research; A.J.M., G.E.O., J.E.L., and S.M. performed research; A.J.M., G.E.O., J.E.L., and E.L.F.H. analyzed data; A.J.M. and E.L.F.H. wrote the paper.

This work was supported by the National Institutes of Health (Grant\#F31NS073196 and Grant \#T32AG000255 to A.J.M., Grant \#F30DK089714 and Grant \#T32AG000255 to J.E.L., Grant \#1K99NS082619 to S.M., and Grant \#GM48661 to E.L.F.H.) and the National Science Foundation (Graduate Research Fellowship Program Grant \#DGE0822 to G.E.0.). We thank lain Cheeseman, Anthony Hyman, Moses Chao, Virginia Lee, Marino Zerial, and Irina Kaverina for generously providing useful reagents.

The authors declare no competing financial interests.

Correspondence should be addressed to Erika L. F. Holzbaur, Department of Physiology, University of Pennsylvania Perelman School of Medicine, 630 Clinical Research Building, 415 Curie Boulevard, Philadelphia, PA 19104-6085. E-mail: holzbaur@mail.med.upenn.edu.

DOI:10.1523/JNEUROSCI.0935-13.2013

Copyright $\odot 2013$ the authors $\quad 0270-6474 / 13 / 3313190-14 \$ 15.00 / 0$
}

Zhang et al., 2011). Recently, we identified a novel function for dynactin in neurons. The CAP-Gly domain of the $\mathrm{p} 150^{\text {Glued }}$ subunit of dynactin is required to promote the efficiency of dynein-mediated retrograde transport from the distal axon (Moughamian and Holzbaur, 2012). This role is highly conserved, because it is also necessary for transport initiation from synaptic termini of neurons in Drosophila (Lloyd et al., 2012). In Perry syndrome, mutations in the CAP-Gly domain block this activity, leading to neurodegenerative disease (Farrer et al., 2009; Moughamian and Holzbaur, 2012).

The CAP-Gly domain is also found in proteins known as cytoplasmic linker proteins (CLIPs), which include CLIP-170 and CLIP-115. The CAP-Gly domain of these proteins binds directly to the $\mathrm{C}$ terminus of $\alpha$-tubulin and also to the end-binding proteins (EBs) EB1 and EB3 (Li et al., 2002; Honnappa et al., 2006; Mishima et al., 2007; Weisbrich et al., 2007). EBs recognize a GTP-tubulin-related structural conformation enriched at the ends of dynamically growing microtubules, and recruit proteins with either a CAP-Gly domain or an SxIP motif to the microtubule plus-end (Honnappa et al., 2009; Maurer et al., 2012). These microtubule plus-end tracking proteins, collectively termed + TIPs, form comet-like accumulations along the ends of polymerizing microtubules (Schuyler and Pellman, 2001) and interact in a network at the microtubule plus-end that regulates microtubule dynamics (Akhmanova and Steinmetz, 2008).

Lis1, another + TIP, is also a dynein regulator (Kardon and Vale, 2009). Mutations in Lis1 cause lissencephaly, so Lis1 has been studied primarily as a modulator of neuronal migration 
(Xiang et al., 1995; Dujardin et al., 2003; Tsai et al., 2007). However, recent work indicates that Lis1 is required for normal retrograde transport in neurons (Pandey and Smith, 2011). Further, Lis1 has been proposed to be a dynein initiation factor in filamentous fungi (Lenz et al., 2006; Egan et al., 2012). Therefore, +TIPs may have a specialized role in intracellular transport in highly polarized cell types.

Here, we examined the role of + TIPs in transport initiation in primary neurons. We found that both EBs and CLIP-170 are necessary for efficient initiation of retrograde transport from the distal axon, whereas Lis1 activates transport through a distinct mechanism. These data support an ordered recruitment model required for efficient transport of multiple cargos, including mitochondria and signaling endosomes, along axonal microtubules.

\section{Materials and Methods}

Cell culture and transfections. Dorsal root ganglia (DRGs) from adult mice $(<1$ year of age) of either sex were dissected and treated with 20 $\mathrm{U} / \mathrm{ml}$ papain for $20 \mathrm{~min}$ at $37^{\circ} \mathrm{C}$, followed by $2 \mathrm{mg} / \mathrm{ml}$ collagenase II and $2.4 \mathrm{mg} / \mathrm{ml}$ dispase II for $20 \mathrm{~min}$ at $37^{\circ} \mathrm{C}$. Neurons were then dissociated in HBSS, supplemented with $5 \mathrm{~mm}$ HEPES and $10 \mathrm{~mm}$ D-glucose, pH 7.35, and purified through a $20 \%$ Percoll gradient for $8 \mathrm{~min}$ at $1000 \times \mathrm{g}$. The basic neuron SCN nucleofector kit (Lonza) was used to transfect DRG neurons with DNA, siRNAs, or both; neurons were then plated onto $0.01 \%$ poly-L-lysine and $20 \mu \mathrm{g} / \mathrm{ml}$ laminin-coated coverslips or glassbottom dishes (FluoroDish; World Precision Instruments). Dissociated DRG neurons were grown for 2-4 d in F-12 medium supplemented with $10 \%$ heat-inactivated FBS and $100 \mathrm{U} / \mathrm{ml}$ penicillin-streptomycin. Livecell imaging was done in Hibernate-A (Brain Bits) supplemented with 2\% B27 supplement (Invitrogen) and 2 mM GlutaMax (Invitrogen). The institutional animal care and use committee at the University of Pennsylvania approved all experiments involving animals.

The dynein heavy chain fused to GFP (DHC-GFP) and GFP-Arp1 HeLa cell lines were obtained from the Hyman laboratory (Max Planck Institute) and the Cheeseman laboratory (Whitehead Institute) (Kiyomitsu and Cheeseman, 2012). Lipofectamine RNAiMax (Invitrogen) was used to transfect siRNA oligonucleotides into HeLa cells, with optimal knock-down achieved at 48-72 h. FuGENE 6 (Promega) was used to transfect DNA plasmids into HeLa cells for no more than $24 \mathrm{~h}$. The cells were plated onto glass-bottom dishes (FluoroDish; World Precision Instruments) for live-cell imaging.

Live-cell microscopy. Distal and mid-axon cargo photobleaching and flux experiments of LAMP1-RFP, DsRed-Mito, pmCherry-Rab5, TrkARFP, TrkB-RFP, and pDsRed-mC1-APP (Fig. $1 F-H$, Fig. $3 A-C$, Fig. $4 A-C$, Fig. $5 E-F$, Fig. $6 A-C$ ) were performed in a temperature-controlled chamber $\left(37^{\circ} \mathrm{C}\right)$ using the Ultraview Vox (PerkinElmer) spinning disk confocal system with an Ultraview Photokinesis (PerkinElmer) unit on an inverted Nikon Ti microscope with apochromat $100 \times 1.49$ numerical aperture (NA) oil-immersion objective and a C9100-50 EM-CCD (Hamamatsu) camera controlled by Volocity software (PerkinElmer). Images were acquired using a $561 \mathrm{~nm}$ laser at 2 frames/s for $5 \mathrm{~s}$ before and for $120 \mathrm{~s}$ subsequent to photobleaching. Photobleaching was performed using the $561 \mathrm{~nm}$ laser at $100 \%$ power for 25 cycles. EB3-GFP dynamics in DRGs (Fig. $1 B, C$ ) were imaged on the Ultraview system described above using a $488 \mathrm{~nm}$ laser at $2 \mathrm{~s}$ per frame for $5 \mathrm{~min}$. DHC-GFP and GFP-Arp1 HeLa cells were imaged on the Ultraview system described above using both the $488 \mathrm{~nm}$ and the $561 \mathrm{~nm}$ laser.

Images of DsRed-Mito motility along the axon (Fig. $5 \mathrm{~A}, \mathrm{C}$ ) were acquired at $1 \mathrm{frame} / 3 \mathrm{~s}$ for $15 \mathrm{~min}$. Images were acquired in epifluorescence on an inverted Leica DMI-6000/CTR-7000HS microscope with an Apochromat $63 \times 1.4$ NA oil-immersion objective in a temperature-controlled chamber $\left(37^{\circ} \mathrm{C}\right.$ ) with an ORCA $\mathrm{R}^{2}$ (Hamamatsu) camera using LAS-AF software (Leica). Fixed DRGs (Fig. 4D,E) were imaged in epifluorescence, as described above, with the addition of a $1.6 \times$ magnifier.

Image analysis. Kymographs of time-lapse imaging data from neurons were constructed using either the ImageJ multiple kymograph plugin (EMBL) or Volocity (PerkinElmer) and quantified in ImageJ. The retro- grade distal and mid-axon flux was measured from kymographs of the photobleached region of the axon, which were made before and subsequent to the photobleaching. Vesicles originating from the distal side that moved at least $3.5 \mu \mathrm{m}$ in the retrograde direction into the photobleached zone were considered retrograde moving cargos. The $3.5 \mu \mathrm{m}$ cutoff was determined to differentiate between cargos actively transported into the photobleached region and those moving more diffusionally into the photobleached region based on experiments in which motility from the distal end was blocked by disruption of the CAP-Gly domain of p150 Glued (Moughamian and Holzbaur, 2012).

Line-scan fluorescence intensity quantification was performed on raw imaging data using MetaMorph. A line starting at the distal end of the neurite was drawn along the process toward the cell body and the florescence intensity was measured along the line. The fluorescence intensity of both channels was normalized to the minimum value of each line. The normalized intensities were divided by the corresponding normalized GFP intensity and the mean intensity in the distal $10 \mu \mathrm{m}$ of the neurite tip was plotted.

For mitochondrial motility along the axon, all tracks from each DsRed-Mito kymograph were classified as either anterograde, retrograde or nonmotile. Cargos that moved net distances $>10 \mu \mathrm{m}$ in a single direction were classified as either anterograde or retrograde. Cargos that moved $<10 \mu \mathrm{m}$ were classified as nonmotile (Maday et al., 2012; Moughamian and Holzbaur, 2012).

Analysis of plus-tip fluorescence intensity in HeLa cells stably expressing GFP-Arp1 and transiently expressing mCherry-EB3 was determined along tracks from maximum projection images of the live-cell movies. The average intensity of GFP-Arp1 along EB3 tracks was determined after background subtraction of the mean GFP-Arp1 fluorescence signal per cell to control for variable expression of the GFP-Arp1.

Protein purification and in vitro microtubule dynamics assay. The p150Nt-GCN4 construct with amino acids $1-210$ of p150 ${ }^{\text {Glued }}$ was fused to a GCN4 coiled coil sequence to drive dimerization, as described previously (Trybus et al., 1997). After expression in Rosetta E. coli (Novagen), p150Nt-GCN4 was affinity purified using a C-terminal 6x-His tag on a $1 \mathrm{ml}$ HisTrap column (GE Healthcare), fluorescently labeled with a HaloTag Alexa Fluor-488 ligand (Promega) and then exchanged into BRB80 (80 mм PIPES, pH 6.8, 1 mм $\mathrm{MgCl}_{2}, 1$ mм EGTA) with $75 \mathrm{~mm}$ $\mathrm{KCl}$ and $10 \%$ glycerol (v/v) by gel filtration on a Superdex 200 10/300 GL column (GE Healthcare). The protein was subsequently aliquoted, flash frozen, and stored in liquid nitrogen. Unlabeled tubulin was purified from bovine brain through two cycles of polymerization and depolymerization in high molarity PIPES buffer as described previously (Castoldi and Popov, 2003). The CLIP-170 H2-GFP fragment and full-length EB1 were purified and fluorescently labeled as described previously (Dixit et al., 2009), except $0.5 \mathrm{M} \mathrm{NaCl}$ and $10 \%$ glycerol were present throughout, and the proteins were gel filtered as described above before aliquoting.

Total internal reflection (TIRF) microscopy (Fig. 2C,D) was performed in a temperature-controlled chamber $\left(37^{\circ} \mathrm{C}\right)$ using an inverted Nikon Ti microscope with a TIRF arm and an apochromat $100 \times 1.49$ NA oil-immersion objective captured on an ImagEM C9100-13 (Hamamatsu) camera controlled by Volocity software (PerkinElmer). Experiments were conducted in flow cells $(\sim 8 \mu$ l in volume) constructed using silanized coverslips (GE Healthcare), as described previously (Dixit et al., 2009). Briefly, $25 \mu \mathrm{M}$ unlabeled tubulin was used to polymerize unlabeled microtubules off of GMPCPP (Jenna) doubled-cycled seeds containing biotin and dimly labeled (1:50) rhodamine-tubulin (Cytoskeleton). Next, 100 nM EB1 and either p150Nt-GCN4 or CLIP-170 H2GFP were added at 10 or $25 \mathrm{~nm}$ concentrations to assess plus-end tracking along dynamic microtubules. The final TIRF mixture contained a final concentration of $50 \mathrm{~mm} \mathrm{KCl}$ and $0.005 \%$ Tween 20 .

siRNAs and plasmids. The sequences of siRNAs oligonucleotides against $\mathrm{p} 150^{\text {Glued }}$ used in DRGs are as follows: GACUUCACCCCUUGAUUAA and CGAGCUCACCACAGACCUG with the corresponding scrambled sequences: GATCCTTTACGTCTCACAA and CCUACGCAAUCCGACCGAG (Dixit et al., 2008; Levy and Holzbaur, 2008).

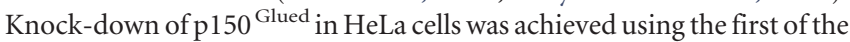
above sequences and the corresponding scrambled control. EB1 and EB3 knock-down in DRG neurons was achieved using the following four 
siRNA oligonucleotides (two against EB1 and two against EB3): UCUUAUAGAUGUCGACUUU, AGAAUAUACAGUACCGUGA, GCAUUAGGGAGCCGGACGA, CCAAACUAGAACACGAGUA, respectively (Moughamian and Holzbaur, 2012). EB1 knock-down in HeLa cells was achieved using the human siRNA ON-TARGETplus SMARTpool (Dharmacon/Thermo Scientific) with the following sequences: AGAUGAAG GCUUUGUGAUA, UGACAAAGAUCGAACAGUU, AAACGACCCU GUAUUGCAG, GGAAAGCUACGGAACAUUG. Knock-down of Lis1 in DRGs was achieved using the mouse siRNA ON-TARGETplus SMARTpool (Dharmacon/Thermo Scientific) with the following sequences: UAUAAGAACAAGCGAUGCA, UGACAAGACCCUCCGUG UA, UCAGCAGAUAUGACGAUUA, GUACGUAUGGUGCGGCCAA. Knock-down of CLIP-170 in DRG neurons was achieved using the mouse siRNA ON-TARGETplus SMARTpool (Dharmacon/Thermo Scientific) with the following sequences: UCAGAAAAGUCCCGAAUA A,GCAGAAGAGUAUUGGCGAA,CUUCAAAGCUAACGAGGAA,GU GUUUGGGUGAACGGGAA. Knock-down of CLIP-170 in HeLa cells was achieved using the human siRNA ON-TARGETplus SMARTpool (Dharmacon/Thermo Scientific) with the following sequences: GAAG AUGCCAUGCAGAUAA, CAGUAUAACUAGUGCCUUA, GCUCAA UAAUCAGUUGUUA, CGACGAAACCUUCUGAUGA. Knock-down of dynein heavy chain in HeLa cells was achieved using GAGAGGAGGUUAUGUUUAA (Caviston et al., 2011). The ON-TARGETplus Nontargeting Pool (Dharmacon/Thermo Scientific) was used as control siRNA oligonucleotides for the EB1 and EB3, Lis1, CLIP-170, and dynein heavy chain knock-down experiments.

The following DNA constructs were used: LAMP1-RFP (Addgene), pDsRed2-Mito (Clontech), pmCherry-Rab5 (gift from M. Zerial, Max Planck Institute), TrkA-RFP and TrkB-RFP (gift from M. Chao, New York University), pDsRed-mC1-APP (gift from V. Lee, University of Pennsylvania), mCherry-EB3 (gift from I. Kaverina, Vanderbilt University) and also subsequently recloned to EB3-GFP. Wild-type and $\Delta$ CAPGly p150 Glued were cloned into the pBI-CMV2 vector (Clontech), $\Delta$ CAP-Gly p150 ${ }^{\text {Glued }}$ lacks the first 93 aa of full-length p150 Glued (Moughamian and Holzbaur, 2012). EGFP-tagged CC1 contains amino acid residues $216-550$ of p 150 Glued.

Immunofluorescence. DRG neurons were fixed in $4 \%$ paraformaldehyde in PBS for 15 min and permeabilized in $0.1 \%$ Triton X-100 in PBS. Cells were blocked with 5\% goat serum and $1 \%$ BSA in PBS. The following primary antibodies were used to stain neurons: p150 Glued (610474; BD Biosciences), Lis1 (L7391; Sigma), GFP (GFP-1020; Aves Laboratories). Species-specific Alexa Fluor-conjugated (Invitrogen) or Cy2conjugated (Aves Laboratories) secondaries were used.

Statistical methods. Statistical analysis was performed in Prism software (GraphPad). Either a Student's $t$ test or one-way ANOVA with a Bonferroni post test was used to determine statistical significance when comparing two datasets or more than two datasets, respectively.

\section{Results}

\section{EB1 and EB3 are required for the efficient initiation of transport from the distal axon}

+ TIPs have been proposed to promote the initial interaction of membranous organelles with microtubules (Pierre et al., 1992; Vaughan et al., 2002). However, in HeLa cells, depletion of EB1 or CLIP-170 does not affect the localization of intracellular cargos significantly or disrupt dynein-mediated ER-to-Golgi transport (Watson and Stephens, 2006). Similarly, deletion of the CAP-Gly domain of dynactin does not affect organelle localization or transport in nonpolarized cells, including S2 and HeLa cells (Kim et al., 2007; Dixit et al., 2008). In contrast, mutation or deletion of the CAP-Gly domain of p150 Glued significantly affects transport efficiency from the distal axon in primary neurons (Moughamian and Holzbaur, 2012), suggesting that highly polarized cells, which require more precise organelle trafficking, may have a unique dependence on +TIPs.

Our previous work indicated that knock-down of EBs by RNAi led to a loss of dynactin accumulation at the distal neurite tip (Moughamian and Holzbaur, 2012). To further examine the role of EBs in axonal transport, in the present study we performed live-cell imaging of primary DRG neurons expressing EB3-GFP to assess microtubule dynamics along the axon. EB3 comets grew uniformly in the anterograde direction in DRG neurites (Fig. $1 B, C)$, confirming the uniform plus-end outward polarity of the microtubule cytoskeleton in this cell type (Maday et al., 2012). Kymographs were generated from time-lapse videos, projecting EB3-GFP intensity along the neurite over time, to assess EB3GFP dynamics and density along the axon (Fig. $1 C$ ); an averaged projection of the EB3-GFP time series (Fig. 1A) served as a marker for neuronal morphology (Kapitein et al., 2010). In the distal axon, but not the mid-axon, we observed the congruent growth of numerous EB3 comets within a single frame (Fig. 1B). Quantitative analysis of EB3-GFP comet density as a function of distance from the distal end of the neurite indicated a significant $(p<0.0001$, one-way ANOVA) 2 -fold enrichment of comets in the distal $10 \mu \mathrm{m}$ of the axon compared with subsequent $10 \mu \mathrm{m}$ regions along the mid-axon (Fig. 1D). Because EBs bind preferentially to the growing end of dynamic microtubules (Maurer et al., 2012), the distal enrichment of EB3 comets we observed suggests that microtubules are more dynamic in the distal axon than in the mid-axon; alternatively, the increased EB3 comet density that we observed may reflect a local increase in the total number of microtubules in the most distal $10 \mu \mathrm{m}$ of the axon.

To assess whether the observed enrichment of EB3 comets in the distal axon is specific to DRG neurons or if it is more broadly observed, we imaged EB3-GFP comets in hippocampal neurons at 10 DIV. Hippocampal neurons at this time point have matured, developing distinct axonal and dendritic processes. We found that the number of EB3-GFP comets per $10 \mu \mathrm{m}$ in the distal axon, $8.5 \pm 0.99$, was $\sim 2$-fold the comet density observed in the mid-axon, $4.2 \pm 0.54$ (data are shown as mean \pm SEM, $n=$ 6 neurons per condition, $p<0.01)$. Therefore, the increased microtubule dynamics observed distally in neurites from DRG neurons was also observed in the distal axons of hippocampal neurons.

We hypothesized that this distal increase in EB3 comet density may promote efficient retrograde transport initiation from the distal axon, because dynactin-mediated transport initiation is dependent on the CAP-Gly domain of p $150^{\text {Glued, }}$, which binds directly to EBs (Berrueta et al., 1999; Askham et al., 2002; Ligon et al., 2003; Bjelić et al., 2012; Moughamian and Holzbaur, 2012). To test this hypothesis, we used a photobleaching assay to assess the number of cargos that initiate retrograde transport from the distal axon (Moughamian and Holzbaur, 2012). Photobleaching all fluorescently labeled cargos in a region-of-interest just proximal to the end of the neurite allowed us to use live-cell imaging to measure more accurately the number of cargos that entered the region from the distal end via retrograde transport (Fig. 1E) without interference from the cargo already moving along the axon.

We used this assay to determine the role of the plus-end proteins EB1 and EB3 in transport initiation by simultaneously depleting EB1 and EB3 from primary neurons. Western blot analysis indicated that endogenous EB1 and EB3 were depleted by $72 \%$ and $94 \%$, respectively, under these conditions. We expressed the fluorescently labeled late endosome/ lysosome cargo marker LAMP1-RFP and performed the photobleaching assay described above (Fig. 1E). For comparison, we also bleached a region along the mid-axon $>100 \mu \mathrm{m}$ 
A
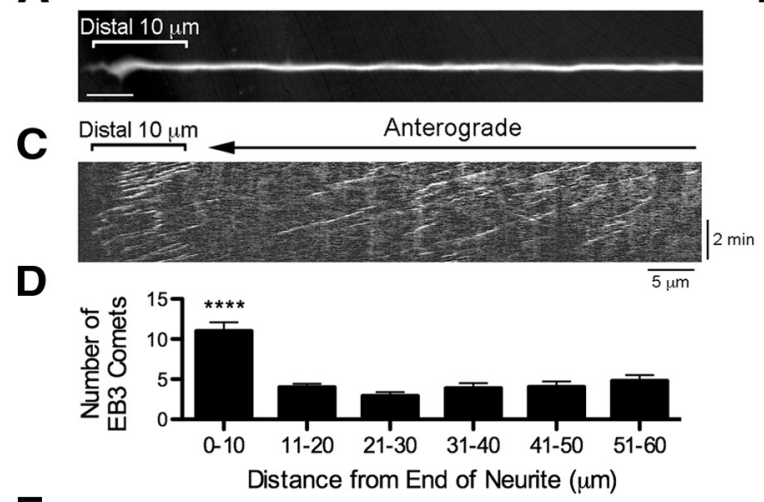

B

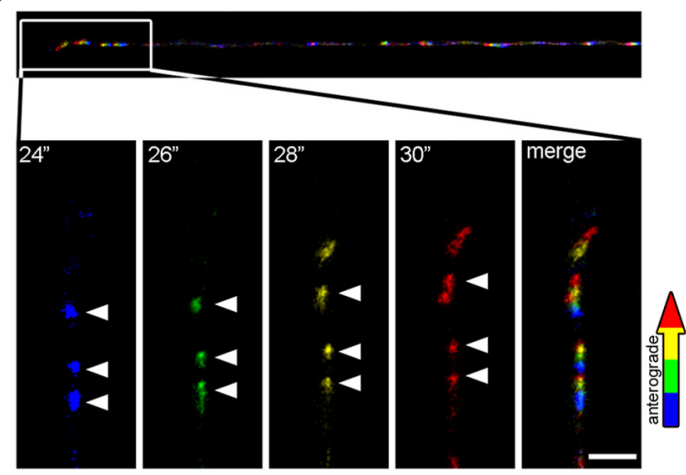

$\mathbf{E}$

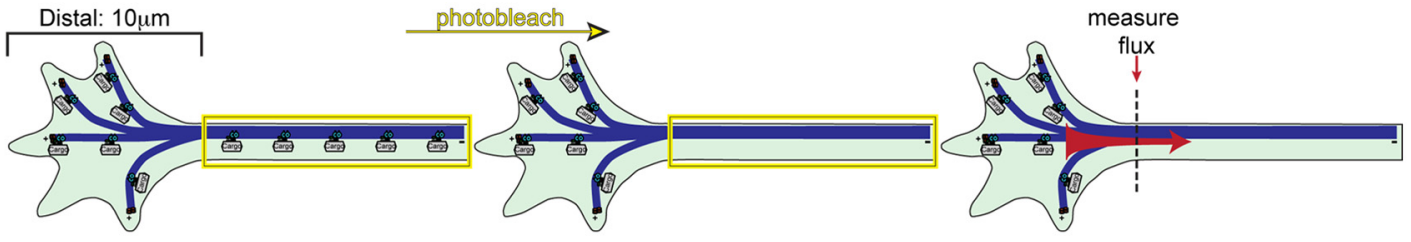

$\mathbf{F}$

Control siRNA

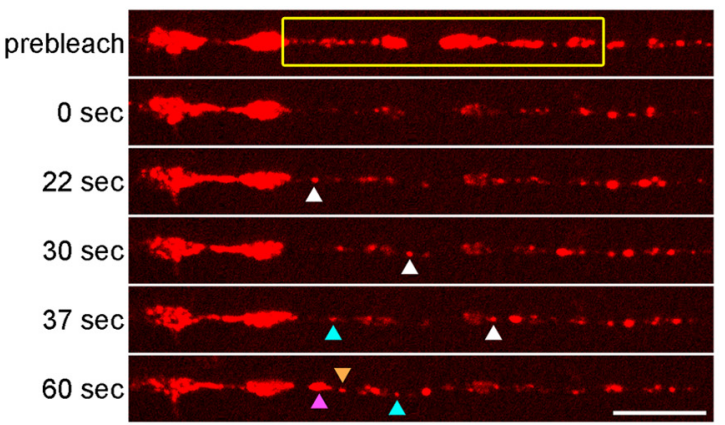

G
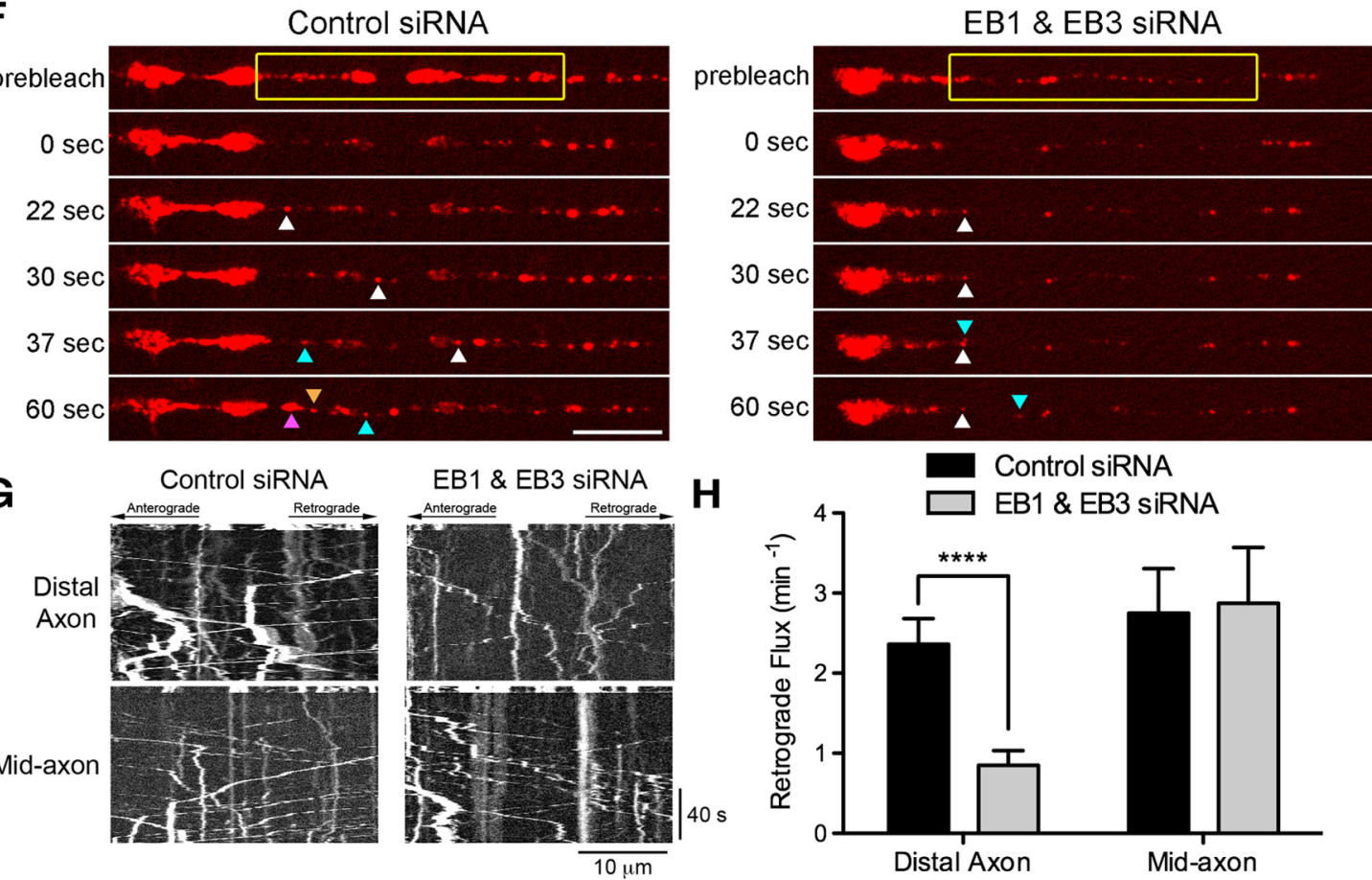

$\mathbf{H}$

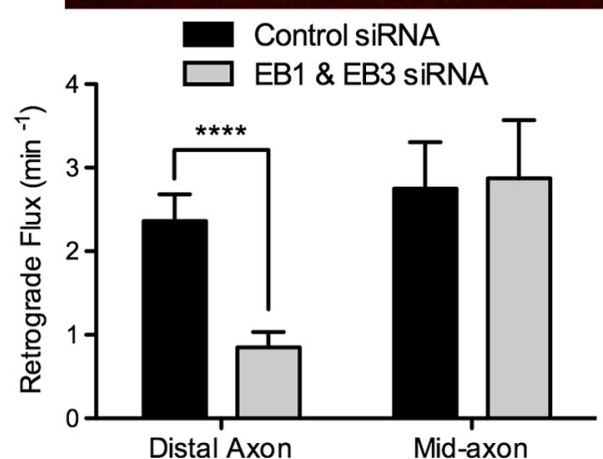

Figure 1. EB proteins are enriched at neurite tips and promote efficient transport from the distal axon. $A$, Morphology of the distal end of a DRG neuron obtained by averaging the time-lapse recording of EB3-GFP. Scale bar, $5 \mu \mathrm{m}$. B. Time series of EB3-GFP comets in the distal axon color coded by frame. Top, Merge of the color-coded time series from the neurite shown in $\boldsymbol{A}$. Bottom, Insets showing enlargements of the box area through time. Arrowheads demarcate numerous anterograde-moving comets in the distal axon. Scale bar, $2 \mu \mathrm{m}$. C, Kymograph of EB3-GFP comets from the neurite shown in $\boldsymbol{A}$ reveals the pronounced enrichment of EB3 comets in the distal $10 \mu$ m of the axon. $D$, Histogram of the number of EB3-GFP comets as a function of distance along the axon. Data are shown as mean \pm SEM; $n=16$ neurites; ${ }^{* * * *} p<0.0001$, one-way ANOVA. E, Schematic of the photobleaching experiment used to assess distal cargo flux. For distal flux, a zone $10 \mu \mathrm{m}$ proximal to the neurite end was photobleached because an increase in dynamic microtubules was observed in the distal $10 \mu \mathrm{m}$ of the neuron, whereas for mid-axon flux, a zone $>100 \mu \mathrm{m}$ proximal to the neurite end was photobleached. Entry of cargos into the bleach zone was assessed with time-lapse imaging; images were acquired at 2 frames/s for $5 \mathrm{~s}$ before photobleaching and $120 \mathrm{~s}$ after photobleaching. $F$, Time series of LAMP1-RFP motility in the distal axon of DRG neurons imaged at 4 DIV. DRG neurons were transfected with either control siRNAs or siRNA against both EB1 and EB3. The yellow box demarcates the photobleached zone; $0 \mathrm{~s}$ is the first frame after photobleaching. The different colored arrowheads demarcate LAMP1-positive cargos moving into the photobleached zone. Scale bar, $10 \mu \mathrm{m}$. G, Kymographs of both the timeseries of the distal axon LAMP1-RFP motility shown in $\boldsymbol{F}$ and the mid-axon LAMP1-RFP motility. Kymographs are of the photobleached zone before and after photobleaching and represent movement over time so that moving organelles appear as diagonal lines whereas stationary organelles appear as vertical lines. Scale bars, $10 \mu \mathrm{m}$ and $40 \mathrm{~s}$ for the and $y$ axes, respectively. $\boldsymbol{H}$, Quantification of distal and mid-axon retrograde flux after photobleaching. Flux was determined by counting the number of retrograde vesicles that moved $>3.5 \mu$ m into the photobleached zone. Data are shown as mean \pm SEM; for distal flux, $n=18-20$ neurites per condition from two independent experiments; for mid-axon flux, $n=12$ neurites per condition; ${ }^{* * * *} p<0.0001$, Student's $t$ test.

from the end of the neurite. We then assayed retrograde flux into the photobleached regions by measuring the number of cargos that moved at least $3.5 \mu \mathrm{m}$ into the photobleached region in the retrograde direction (see Materials and Methods).
Knock-down of EB1 and EB3 significantly reduced the number of LAMP1-RFP-positive cargos exiting the distal neurite (Fig. $1 F-H)$. This decrease in flux was specific for the distal neurite, because mid-axon flux was unaffected by the depletion of EBs 
(Fig. $1 F-H$ ). The specificity of EB knock-down for disrupting distal flux without affecting mid-axon flux is similar to the regional specificity observed upon either deletion of the CAP-Gly domain of dynactin or expression of a mutant form of dynactin with decreased binding affinity for EB1 (Moughamian and Holzbaur, 2012). These data suggest that both EBs and dynactin are required to promote the efficient initiation of transport from the distal neuron.

Plus-end interacting proteins have also been implicated in neurite extension in tissue culture cells (van Haren et al., 2009). However, in primary DRG neurons under our culture and knock-down conditions, we observed no change in average neurite length after EB1 and EB3 depletion compared with controls; the average neurite length was $781.5 \pm 42.83 \mu \mathrm{m}$ (data are shown as mean \pm SEM) for neurons depleted of EB1 and EB3 versus $751.2 \pm 36.15 \mu \mathrm{m}$ for control neurons. Dynein knock-down was similarly shown not to disrupt neurite outgrowth, likely due to the gradual depletion of target protein by siRNA (He et al., 2005). We also did not observe a difference in the area occupied by LAMP1-RFP-postive organelles in the distal neurite after EB1 and EB3 knock-down: $9.6 \mu \mathrm{m}^{2} \pm 1.1$ (data are shown as mean \pm SEM) for neurons depleted of both EB1 and EB3 versus 9.4 $\mu \mathrm{m}^{2} \pm 0.7$ for control neurons. As we noted previously in our analysis of the role of the CAP-Gly domain of dynactin in transport initiation (Moughamian and Holzbaur, 2012), defects in transport initiation do not necessarily lead to distal accumulation of cargos in the DRG system. In contrast, parallel studies on the role of the CAP-Gly domain of dynactin in Drosophila showed clear accumulations of cargo in synaptic boutons (Lloyd et al., 2012). Therefore, although our DRG model system was sufficiently sensitive to detect changes in the efficiency of transport initiation, the extent of disruption may have not been sufficient to induce the frank accumulation of organelles over the time scale of the assay. Alternatively, there may have been some compensation at the cellular level to prevent the distal accumulation that is not seen in the Drosophila system.

\section{Ordered recruitment of +TIPs to the dynamic microtubule plus-end}

Both dynactin and dynein have been observed to accumulate at the plus-end of microtubules (Vaughan et al., 1999; Zhang et al., 2003; Dixit et al., 2008). EB3 is enriched more than twofold in the distal $10 \mu \mathrm{m}$ of the neurite in DRG neurons (Fig. 1C,D), and we have found that knock-down of EBs leads to depletion of dynactin from the neurite tip (Moughamian and Holzbaur, 2012). Because the CAP-Gly domain of dynactin binds directly to EB1 (Fig. 2A; Askham et al., 2002; Ligon et al., 2003), we hypothesized that EBs increase the efficiency of transport from the distal axon by recruiting dynactin to microtubule plus-ends, which are enriched in this region of the cell.

We used a minimal in vitro system to determine whether EB1 is sufficient to recruit $\mathrm{p} 150^{\text {Glued }}$ to the microtubule plus-end. We reconstituted the dynamic instability of microtubules in vitro by incubating stabilized microtubule seeds with $25 \mu \mathrm{M}$ tubulin dimers (Fig. 2B), conditions favoring stochastic alterations between phases of microtubule polymerization and depolymerization, as demonstrated previously (Bieling et al., 2007; Bieling et al., 2008; Brouhard et al., 2008; Dixit et al., 2009). The resulting dynamics of microtubule growth and shortening, punctuated by catastrophe and rescue events, respectively, can be monitored using TIRF microscopy. The addition of purified recombinant EB1 to this assay reconstitutes the prominent plus-end tracking observed in vivo (Akhmanova and Steinmetz, 2008). Although
EB1 is sufficient to track growing microtubule plus-ends in vitro, previous work has shown that the plus-tip-tracking protein CLIP-170 is not. The addition of CLIP-170 to purified tubulin dimers undergoing dynamic polymerization/depolymerization from microtubule seeds shows binding and diffusion along the microtubule lattice but no preference for binding to the plus tip. Strikingly, the addition of EB1 is both necessary and sufficient to induce the active tip-tracking of the $\mathrm{H} 2$ construct of CLIP-170 (Bieling et al., 2008; Dixit et al., 2009), as shown in Figure 2C.

We used this assay to determine whether EB1 was also necessary and sufficient to induce the plus-tip tracking of p150 Glued seen in live-cell imaging (Vaughan et al., 1999; Dixit et al., 2008). Because full-length recombinant $\mathrm{p} 150^{\text {Glued }}$ is not soluble, we used a purified recombinant construct of p150 Glued (p150NtGCN4) spanning amino acid residues 1-210, which includes the CAP-Gly domain (Fig. 2A). We fused this domain to a short GCN4-coiled coil at the C-terminal to drive dimerization in vitro consistent with the dimeric structure of native p150 Glued within the dynactin complex (Schroer, 2004). Gel-filtration, crosslinking, and hydrodynamic assays confirmed that the purified recombinant p150Nt-GCN4 construct was soluble, monodisperse, and homodimeric. Recombinant p150Nt-GCN4 dimers bound microtubules with a micromolar $K_{\mathrm{d}}$ similar to full-length polypeptide expressed in mammalian cells (data not shown).

Surprisingly, we found that whereas p150Nt-GCN4 bound to the microtubule lattice, this polypeptide did not plus-end track along growing microtubules in the absence (Lazarus et al., 2013) or presence of EB1 at multiple concentrations examined (Fig. $2 D)$. Under all conditions examined, p150 Glued displayed no preference for the microtubule plus-end, but rather bound to and diffused along the microtubule lattice (Fig. 2D). The lattice labeling is most clearly visible at the higher concentration of p150NtGCN4 examined ( 25 nm; Fig. 2D, bottom).

These results suggest that EB1 is not sufficient to recruit p $150^{\text {Glued }}$ to the microtubule plus-end in the cell. To explore further the mechanisms of dynactin recruitment to the microtubule plus-end, we used two HeLa cell lines stably expressing either the fluorescently labeled dynactin subunit GFP-Arp1 or DHC-GFP. These stable cell lines exhibit normal dynein and dynactin localization and function (Kiyomitsu and Cheeseman, 2012). The stable expression of fluorescent dynactin and dynein and the spatially dispersed microtubule array of these cells allowed us to visualize more clearly the recruitment of dynactin and dynein to the microtubule plus-end. Using live-cell fluorescence microscopy, we observed that both GFP-Arp1 and DHCGFP tracked along the growing microtubule plus-end (Fig. 2E). A single frame from the resulting live-cell image stack revealed that dynactin and dynein form bright comet-like structures concentrated at the cell periphery, whereas the maximum projection of the image stack shows the path formed by the dynamic tracking of dynactin and dynein along the microtubule plus-end (Fig. 2E). To confirm that these comet-like structures were indeed accumulations of dynactin at the microtubule plus-end, we transfected the GFP-Arp1 cells with mCherry-EB3. Live-cell fluorescence microscopy revealed that Arp1 and EB3 colocalize along dynamically growing microtubules (Fig. $2 F$ ).

We first used siRNA to deplete endogenous p150 Glued from HeLa cells stably expressing either GFP-Arp1 or DHC-GFP. Knock-down of $\mathrm{p} 150^{\text {Glued }}$ in the GFP-Arp1 and DHC-GFP HeLa cells disrupted the recruitment of these GFP constructs to the microtubule plus-end, as shown by a complete loss of the comet-like structures (Fig. 2E). Maximum projections from the resulting live-cell imaging stack revealed only diffuse fluorescence in both cell lines 
A

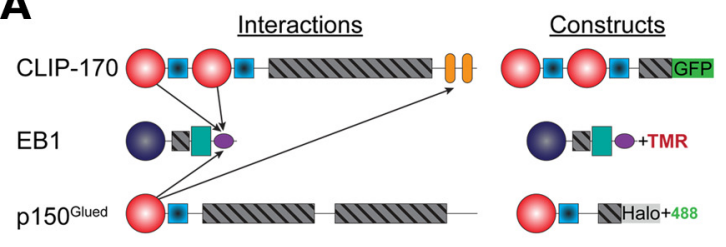

B

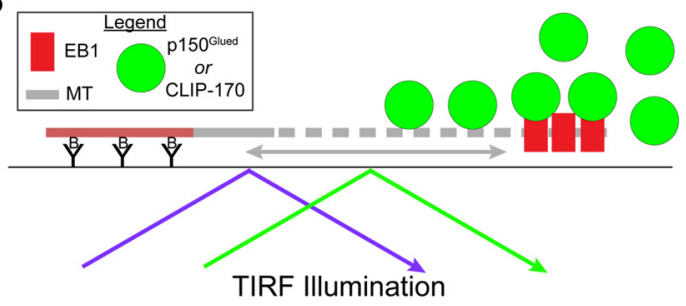

D

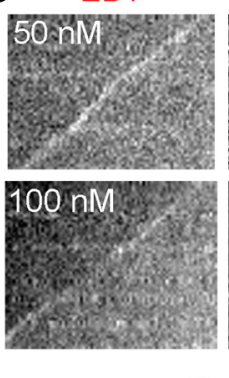

p150-Halo

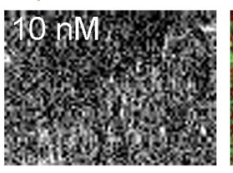

Merge

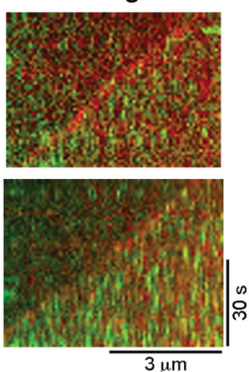

Max Projection
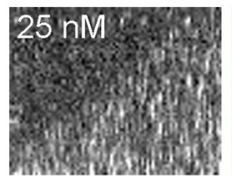

E

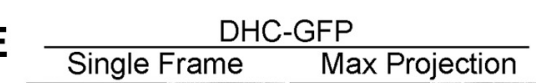
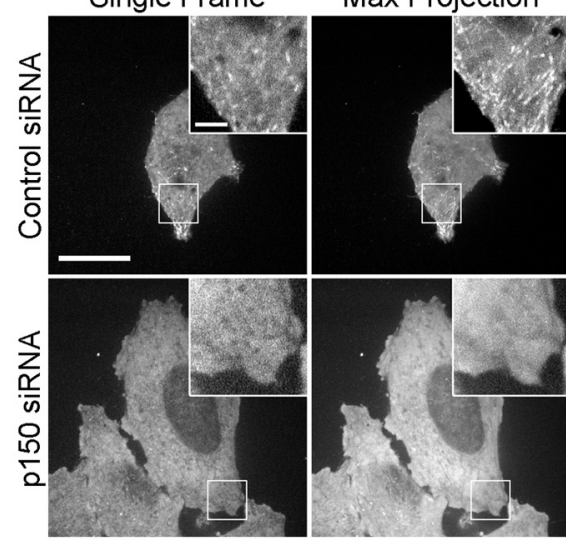

GFP-Arp1

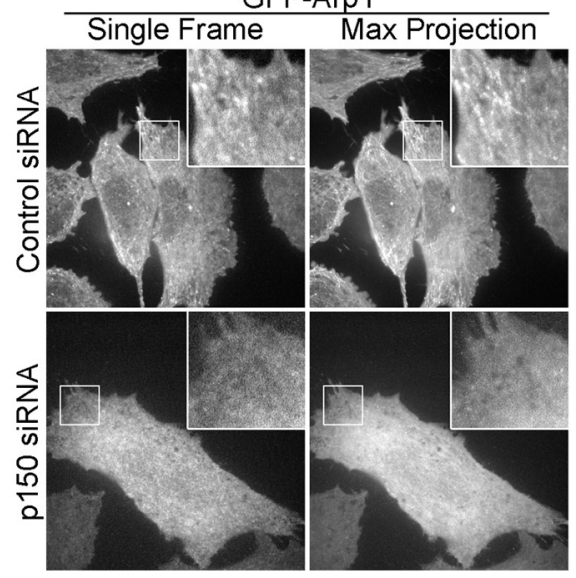

$\mathbf{F}$

Arp1

EB3
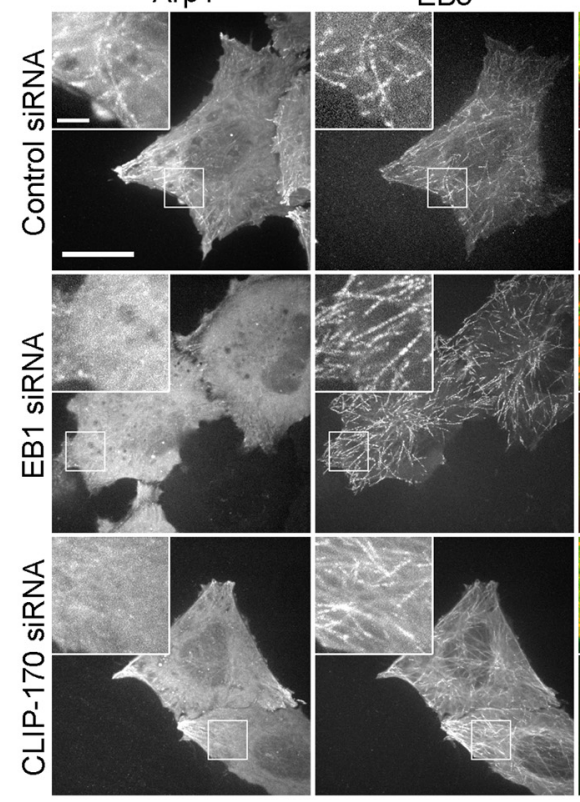

Merge

G

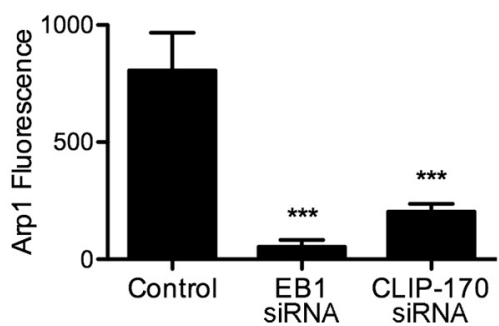

Figure 2. EB1 is required but is not sufficient for microtubule plus-end tracking by dynactin. $A$, Domain organization and binding interactions of the + TIPS CLIP-170 EB1 and p150 Glued and schematics of the constructs used in the in vitro assays shown in $\mathbf{C}$ and $\boldsymbol{D}$. B, Schematic of the in vitro TIRF assay in which microtubule dynamics were reconstituted with purified tubulin. EB1 and either p150 Glued or CLIP-170 was added to assay microtubule plus-end tracking. C, D, Kymographs from the in vitro reconstitution of microtubule dynamics imaged with TIRF microscopy. EB1 was labeled directly with rhodamine dye, the p150-Halo fragment was labeled with an Alexa Fluor-488 Halo ligand, and the CLIP-170 H2 fragment was expressed with a GFP-tag. EB1 and CLIP-170 (C) or EB1 and $150^{\text {Glued }}(\boldsymbol{D})$ were added to the imaging chamber containing dynamic microtubules. EB1 dynamically tracks along the growing microtubule plus-end. EB1 effectively recruits CLIP-170 but is not sufficient to recruit p $150^{\text {Glued }}$ to the dynamic microtubule plus-end. $\boldsymbol{E}$, HeLa cells stably expressing either DHC-GFP or GFP-Arp1 were treated with control siRNA or siRNA against p 150 Glued and then live-cell imaging was performed. Single frames from the image stack reveal bright, comet-like structures, whereas the maximum projection of the image stack reveals extended tracks. Both of these observations are consistent with the dynamic tracking of dynein and dynactin along the microtubule plus-end. Knock-down of p $1500^{\text {Glued }}$ abolishes the plus-end localization of both dynein and dynactin. $\boldsymbol{F}$, Maximum projections from live-cell imaging of HeLa cells stably expressing GFP-Arp1. Cell were transfected with mCherry-EB3 and treated with control siRNA, siRNA against EB1, or siRNA against CLIP-170. The colocalization of GFP-Arp1 with mCherry-EB3 is abolished by knock-down of either EB1 or CLIP-170. G, Average intensity of GFP-Arp1 fluorescence along EB3 tracks from maximum projection images from control cells stably expressing GFP-Arp1 or from GFP-Arp1 cells depleted of either EB1 or CLIP-170. Data are shown as mean \pm SEM; $n=10$ tracks per condition; ${ }^{* * *} p<0.001$, one-way ANOVA. Scale bars, 20 and $3 \mu \mathrm{m}$ for the inset unless otherwise noted. 
after p150 Glued knock-down (Fig. 2E). These results show that the $\mathrm{p} 150^{\text {Glued }}$ subunit is necessary for the plus-end tracking of both dynactin and dynein in mammalian cells, as previously suggested by studies in filamentous fungi (Schuster et al., 2011).

We next used siRNA to knock-down EB1 in the GFP-Arp1 cells. Because HeLa cells express relatively little EB3 (Stepanova et al., 2003), simultaneous knock-down of EB3 was not necessary in this system. We found that depletion of EB1 was sufficient to disrupt the plus-end tracking of dynactin (Fig. $2 F$ ). To quantitate this effect, we expressed mCherryEB3 at low levels; EB3 has a tenfold lower affinity for the CAP-Gly domain of p150 Glued (Bjelić et al., 2012), so we predicted that low-level expression would allow us to visualize microtubule plus-end dynamics without rescuing the EB1 knock-down phenotype. We used the maximum projection image of the resulting live-cell movies to measure the average GFP-Arp1 fluorescence along the growing microtubule end. Depletion of EB1 was sufficient to induce a significant reduction in the average GFP-Arp1 fluorescence at the microtubule plus-end compared with control-treated cells (Fig. 2G).

CLIP-170 bound both to EBs and to p150 Glued (Fig. 2A) and has been implicated in the recruitment of dynactin to the microtubule plus-end (Valetti et al., 1999; Lansbergen et al., 2004). We used HeLa cells stably expressing GFP-Arp1 to examine the role of CLIP-170 in the recruitment of dynactin to the microtubule plus-end. Knock-down of CLIP-170 using siRNA dramatically reduced the amount of dynactin associated with the microtubule plus-end (Fig. 2F). After depletion of CLIP-170, the maximum projection of GFP-Arp1 localization from the live-cell imaging time series showed a diffuse and cytoplasmic pattern, whereas after control siRNA treatment, the maximum projection revealed tracks formed by the dynamic growth of the microtubule. Further, after CLIP-170 depletion, we no longer observed colocalization of GFP-Arp1 with mCherry-EB3 along the microtubule track (Fig. $2 F$ ) and observed a significant decrease in the average intensity of GFP-Arp1 fluorescence at the plus-end (Fig. 2G). Therefore, consistent with previous observations (Lansbergen et al., 2004), both EBs and CLIP-170 are required for dynamic plusend tracking of dynactin in the cell. Both in vitro reconstitution experiments and cellular assays indicate that although EB1 is necessary and sufficient to recruit CLIP-170 to the microtubule plusend (Bieling et al., 2008; Dixit et al., 2009), EB1 is not sufficient to recruit dynactin: CLIP-170 is also required. These observations support an ordered recruitment pathway for plus-end localization of these proteins in the cell.

\section{CLIP-170 is necessary for efficient transport initiation from} the distal axon, whereas Lis1 is required for sustained transport along the axon

CLIP-170 is thus a key mediator required for the recruitment of dynactin to the microtubule plus-end. However, depletion of CLIP-170 from HeLa cells did not affect organelle localization or trafficking (Watson and Stephens, 2006), similar to the observa- tion that the CAP-Gly domain of dynactin is not required for normal organelle transport in HeLa cells (Dixit et al., 2008). We wondered whether there might be a neuron-specific role for the ordered recruitment of + TIPs observed both in vitro and in cellular assays.

We hypothesized that CLIP-170 might be specifically required for initiation of retrograde axonal transport from the distal axon. We tested this hypothesis using the photobleaching assay described above (Fig. 1E). Measurements of cargo flux from the distal axon reveal a significant inhibition in transport after CLIP170 knock-down compared with control neurons (Fig. 3A-C). For comparison, we also assayed flux along the mid-axon, but did not see a significant difference in the axonal transport of late endosomes and lysosomes in this region upon CLIP-170 depletion (Fig. $3 B, C$ ). This regional specificity of the effects of CLIP170 depletion provides further support for a specific role for a +TIP-dependent transport initiation mechanism at the distal neurite that is not required for bulk transport along the length of the neurite.

+ TIPs have been implicated in the regulation of microtubule dynamics (Komarova et al., 2009; Stepanova et al., 2010), so the decrease in retrograde flux observed upon knock-down of either EBs or CLIP-170 could be due to alterations in these dynamics. To test this possibility, we measured microtubule dynamics in DRG neurons after knock-down of CLIP-170. We found no difference in the number of distal or mid-axon EB3 comets between control and CLIP-170 siRNA-treated neurons. For the distal 10 $\mu \mathrm{m}$ of the axon, we observed $9.6 \pm 0.93$ comets for controltreated neurons compared with $9.9 \pm 0.694$ comets after CLIP170 knock-down (data are shown as mean \pm SEM, $n=10-11$ neurites, $p>0.05)$. In the mid-axon, we observed $4.9 \pm 1.22$ comets per $10 \mu \mathrm{m}$ for control neurons compared with $5.66 \pm$ 0.47 comets per $10 \mu \mathrm{m}$ after CLIP-170 knock-down (data are 
A

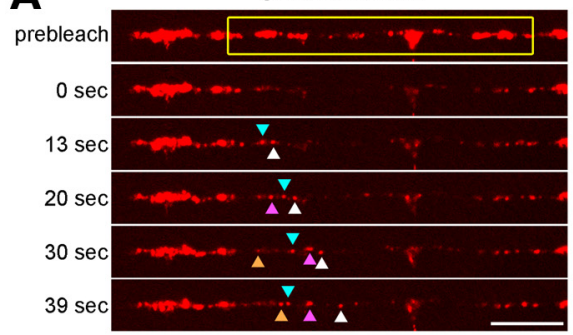

B
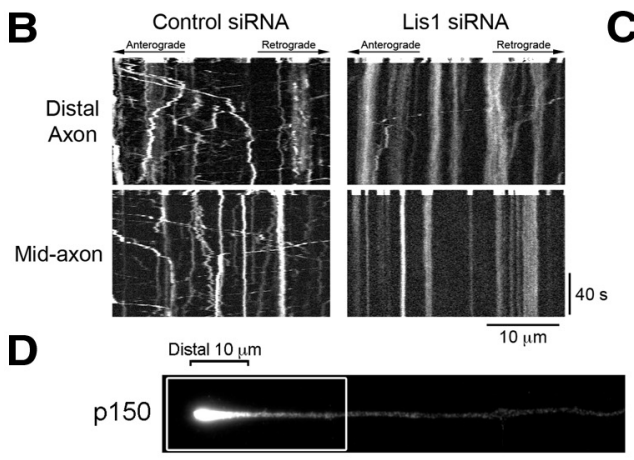

$\mathbf{E}$

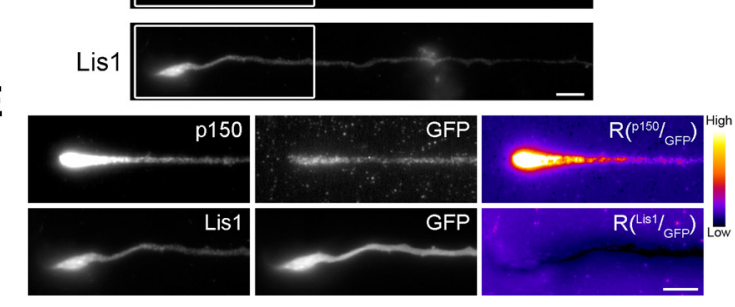

Lis1 siRNA

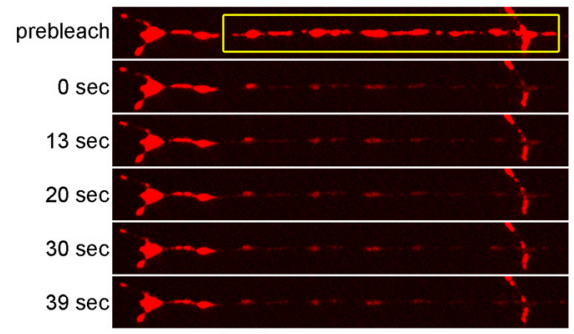

Control siRNA

\section{(3)}

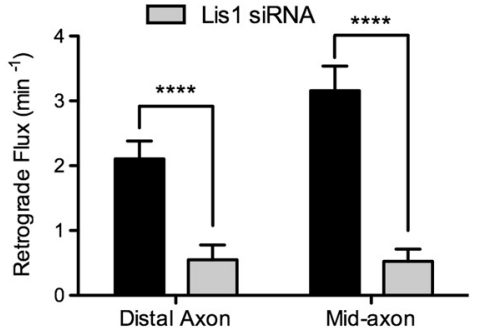

$\mathbf{F}$

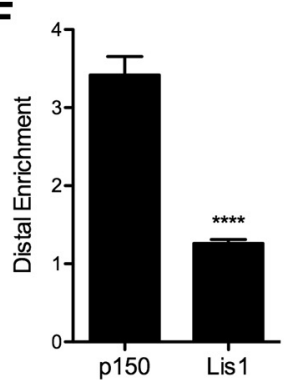

Figure 4. Lis1 is necessary for retrograde transport initiation from both the distal and mid-axon. $\boldsymbol{A}$, Time series of LAMP1-RFP motility in the distal axon of DRG neurons imaged at 4 DIV. DRG neurons were transfected with either control siRNAs or siRNA against Lis1. The yellow box demarcates the photobleached zone; $0 \mathrm{~s}$ is the first frame after photobleaching. The different colored arrowheads demarcate LAMP1-RFP-positive cargos moving into the photobleached zone. No cargos entered the photobleached zone after Lis1 knock-down. Scale bar, $10 \mu \mathrm{m}$. B, Kymographs of the time series of the distal axon LAMP1-RFP motility shown in $A$ and the mid-axon LAMP1-RFP motility. Scale bars, $10 \mu \mathrm{m}$ and 40 s for the $x$ and $y$ axes, respectively. C, Quantification of distal and mid-axon retrograde flux after photobleaching. Flux was determined by counting the number of retrograde vesicles that moved $>3.5 \mu \mathrm{m}$ into the photobleached zone. Data are shown as mean \pm SEM; for distal and mid-axon flux, $n=19-20$ neurites per condition from two independent experiments. D, Distal end of DRG neurons at 2 DIV stained for the endogenous $p 150$ Glued subunit of dynactin and endogenous Lis1. Scale bar, $5 \mu \mathrm{m}$. $\boldsymbol{E}$, Enlarged view of the distal end of DRG neurons. Neurons were transfected with GFP as a marker of cytoplasmic volume and stained for either $\mathrm{p} 150^{\text {Glued }}$ or Lis1. The p150, Lis1, and GFP images were individually contrast enhanced to display both axonal and tip staining. The raw p150 and Lis 1 signals were divided by the corresponding raw GFP signal to create the ratio image $\left(R^{\mathrm{p} 150} /_{\text {GFP }}\right.$ or $R^{\text {Lis } 1} /$ GFP $)$. These ratio images show the distal accumulation of p150 Glued or Lis1 relative to GFP. These ratio images were contrast enhanced to the same level. A heat map was applied (warmer colors represent a higher ratio, whereas cooler colors represent a lower ratio) to show the relative intensities. Scale bar, $5 \mu \mathrm{m}$. $\boldsymbol{F}$, Quantification of the distal enrichment. The mean $\mathrm{p} 150^{\text {Glued }}$ and Lis 1 fluorescence intensity in the distal $10 \mu \mathrm{m}$ of the axon was measured and then normalized to corresponding mean GFP intensity. The normalization controls for differences in the cytoplasmic volume so that the value represents the enrichment of $p 150$ Glued or Lis 1 in the distal axon. Data are shown as mean $\pm \mathrm{SEM} ; n=$ $59-65$ neurites per condition; ${ }^{* * * *} p<0.0001$, Student's $t$ test.

shown as mean \pm SEM, $n=10-11$ neurites, $p>0.05)$. The twofold enrichment in EB3 comet density in the distal axon compared with the mid-axon was not affected by CLIP-170 knockdown. We also found no significant difference in either comet velocity $(9.25 \pm 0.17 \mu \mathrm{m}$ per minute for control neurons compared with $8.89 \pm 0.14 \mu \mathrm{m}$ per minute after CLIP-170 knock-down, data are shown as mean \pm SEM, $n>319$ comets, $p>0.05$ ) or distance to catastrophe (3.48 $\pm 0.15 \mu \mathrm{m}$ for control compared with $3.30 \pm 0.13$ $\mu \mathrm{m}$ after CLIP-170 knock-down, data are shown as mean \pm SEM, $n>319$ comets, $p>0.05$ ). Although previous studies in hippocampal neurons cultured from CLIP-170 knock-out mice revealed a significant increase in comet length (Stepanova et al., 2010), the magnitude of the effect was quite limited and no decrease in comet density was reported. Under our conditions, the knock-down of

CLIP-170 resulted in a significant inhibition of transport initiation from the distal axon (Fig. 3C) without disrupting microtubule dynamics.

We next focused on the role of the +TIP Lis1 because it has recently been proposed to act as an initiation factor for dynein-mediated transport. In live-cell assays in filamentous fungi, Lis1 is required for dynein-mediated transport from the distal hyphae, but detaches from the dynein complex shortly after transport is initiated (Lenz et al., 2006; Egan et al., 2012). Lis1 has not been shown to be necessary for dynein-mediated transport in nonpolarized mammalian cells; however, it is required for the transport of at least a subset of cargos along the axons of neurons (Liu et al., 2000; Pandey and Smith, 2011; Yi et al., 2011).

We compared the requirements for Lis1 in dynein-mediated transport initiation and the maintenance of sustained axonal transport in primary DRG neurons. We achieved 54\% knock-down of Lis1 in DRG neurons using siRNAs against Lis1. Using the photobleaching assay described in Figure 1E, we examined the retrograde flux of LAMP1-positive organelles from the distal axon after Lis1 knock-down and observed that significantly fewer cargos exited the distal axon in Lis1-depleted neurons compared with control neurons (Fig. 4A). We also assessed retrograde flux along the mid-axon in Lis1-depleted neurons. Here, in contrast to our observations in dynactin-, EB-, or CLIP-170-depleted neurons, we observed that significantly fewer LAMP1-RFP-positive organelles entered the photobleached zone compared with control neurons (Fig. 4B). Quantification of the retrograde flux indicates that Lis1 depletion resulted in a significant reduction in both distal and midaxon flux compared with measurements in control siRNA-treated neurons (Fig. 4C). Therefore, Lis1 is necessary for both initiation of transport from the distal axon and continued transport along the mid-axon. Yi et al. (2011) suggested that Lis1 might be specifically required only for the transport of large $(>1 \mu \mathrm{m})$, lysotracker-positive degradative organelles, possibly due to the promotion of a high-load dynein state required to move these cargos effectively along the axon. However, we have previously isolated and characterized LAMP1-positive late endosomes/lysosomes from mouse brain and found an average diameter of $90 \mathrm{~nm}$ (Hendricks et al., 2010). Further, our transport studies indicated a uniform inhibition of LAMP-1-postive organelles rather than an effect specific for larger cargos (Fig. 4A). Our results therefore favor a broader role for Lis 1 in organelle transport in the neuron.

Live-cell imaging results suggest that the role of Lis1 is not limited to an effect on transport initiation from the distal axon. Therefore, we would not expect to see the same distal enrichment 
of Lis1 as was observed previously for dynactin (Moughamian and Holzbaur, 2012) and EB1 (Fig. 1A-C). To test this prediction, we stained DRG neurons for endogenous Lis1 and dynactin (Fig. 4D). Dynactin was enriched in the distal $10 \mu \mathrm{m}$ of the axon, consistent with our previous observations (Moughamian and Holzbaur, 2012); in contrast, there was no distal enrichment of Lis1. Neurons were transfected with GFP, as a marker of cytoplasmic volume, and stained for either p $150^{\text {Glued }}$ or Lis 1 . When the p $150^{\text {Glued }}$ or Lis1 fluorescence signal was divided by their corresponding soluble GFP control fluorescence, there was a clear enrichment of dynactin distally but no similar enrichment of Lis1 (Fig. 4E, F). These data show that Lis1 and dynactin localize to distinct pools in the axon, although both are required for active axonal transport.

\section{Dynactin is necessary for transport initiation of multiple cargo types}

Thus far, we have focused on the mechanisms of transport initiation for a single model cargo, LAMP1-positive late endosomes/lysosomes. However, the dyneindynactin complex is the primary retrograde motor in neurons and thus drives the motility of a wide range of cargos, including endosomes, mitochondria, and autophagosomes. Strikingly, many of these dyneindriven cargos exhibit dramatically different patterns of motility along the same axon. For example, LAMP1-positive late endosomes/lysosomes move robustly in both the anterograde and retrograde directions and undergo very frequent directional reversals, whereas APP-positive organelles move rapidly and processive along the axon with few pauses or switches (Hendricks et al., 2010; Reis et al., 2012). Therefore, we investigated whether the initiation of retrograde transport for cargos other than lysosomes involves the same EB/CLIP-170/dynactindependent pathway or if this mechanism is cargo specific.

First, we examined the transport of mitochondria. Mitochondria are large organelles that exhibit highly regulated bidirectional motility (Saxton and Hollenbeck, 2012), which has been shown to be due to the opposing activities of kinesin and dynein motors (Pilling et al., 2006). We used a dominant-negative approach to test the requirement for dynein and dynactin in mitochondrial motility along axons of DRG neurons. We expressed CC1, a potent dominant-negative inhibitor of dynein (Quintyne et al., 1999), in primary DRG neurons and assayed mitochondrial motility along the axon (Fig. 5A). As was shown recently for mitochondrial transport along the axons of hippocampal neurons (van Spronsen et al., 2013), expression of CC1 dramatically disrupted the bidirectional transport of mitochondria. We observed significant decreases in the number of both anterograde and retrograde moving mitochondria and a significant increase in the number
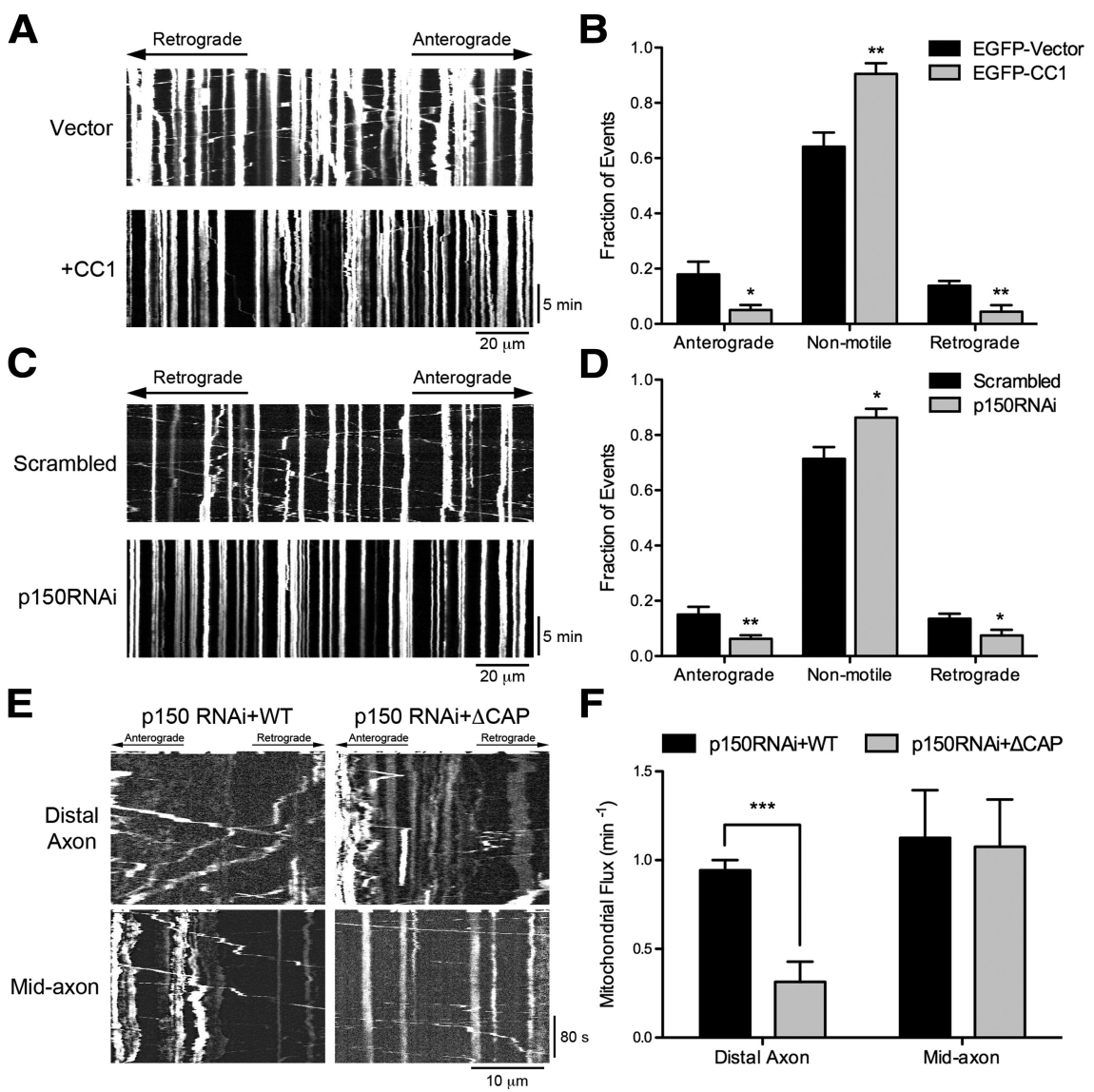

Figure 5. Dynein-dynactin is required for the bidirectional transport of mitochondria and efficient initiation of transport from the distal axon. $A$, Kymographs of DsRed-Mito motility along the axon of DRG neurons imaged at 2 DIV after transfection with either EGFP or EGFP-CC1. Images were acquired at 1 frame $/ 3 \mathrm{~s}$ for $15 \mathrm{~min}$. Scale bars, $20 \mu \mathrm{m}$ and $5 \mathrm{~min}$ for the $x$ and $y$ axes, respectively. B, Quantification of mitochondrial motility after $\mathrm{CC} 1$ transfection. Mitochondrial moving $>10 \mu \mathrm{m}$ in either direction along the length of the kymograph were considered anterograde or retrograde, whereas cargos moving $<10 \mu \mathrm{m}$ were considered nonmotile. Expression of $\mathrm{CC} 1$ significantly disrupts anterograde and retrograde motility and increases nonmotile events. Data are shown as mean \pm SEM; $n=6-7$ neurites per condition. C, Kymographs of DsRed-Mito motility along the axon of DRG neurons imaged bars, $20 \mu \mathrm{m}$ and $5 \mathrm{~min}$ for the $x$ and $y$ axes, respectively. D, Quantification of mitochondrial motility after $p 150^{\text {Glued }}$ knock-down, s described in $\boldsymbol{B}$. Depletion of p150 Glued significantly disrupts the bidirectional transport of mitochondria. Data are shown as kock-down of p $150^{\text {Glued }}$ and rescue with either full-length wild-type $150^{\text {Glued }}$ or $\Delta$ CAP-Gly p $150^{\text {Glued. }}$. For distal flux, a zone 10 . Kymographs are of the photobleached zone before and after photobleaching. Scale bars, $10 \mu \mathrm{m}$ and $80 \mathrm{~s}$ for the of retrograde vesicles that moved $>3.5 \mu \mathrm{m}$ into the photobleached zone. Data are shown as mean $\pm \mathrm{SEM}$; for distal flux, $n=7$ neurites per condition; for mid-axon flux, $n=8$ neurites per condition; ${ }^{* * *} p<0.001,{ }^{* *} p<0.01,{ }^{*} p<0.05$, Student's $t$ test.

of nonmotile mitochondria after expression of $\mathrm{CC} 1$ compared to control neurons (Fig. 5B). To confirm this observation, we used siRNA to knock down the $\mathrm{p} 150^{\text {Glued }}$ subunit of dynactin by $80 \%$ compared with scrambled control-treated neurons. Knock-down of p150 Glued disrupted the bidirectional transport of mitochondria (Fig. 5C). We observed a significant decrease in both the number of anterograde and retrograde moving mitochondria and a corresponding increase in the number of nonmotile mitochondria (Fig. 5D).

These data show that dynein-dynactin activity is required for mitochondrial transport along the axons of mammalian DRG neurons. Either dominant-negative inhibition of dynein-dynactin function or depletion of dynactin by RNAi leads to a bidirectional block in the axonal transport of mitochondria. In 
non-neuronal cells, CC1 expression induces a complete inhibition of motility of some cargos (endosomes and lysosomes; Quintyne et al., 1999), but depletion of dynein by RNAi does not inhibit anterograde motility of other cargos, including late endosomes and lysosomes, which accumulate at the cell periphery (Caviston et al., 2011). In neurons, however, we and others have observed that the inhibition of the retrograde axonal transport machinery often results in a bidirectional block in transport (Waterman-Storer et al., 1997; Martin et al., 1999; Hendricks et al., 2010; van Spronsen et al., 2013). The mechanisms leading to tight coupling of anterograde and retrograde motors on cargos undergoing axonal transport remain to be determined, but may involve scaffolding proteins such as huntingtin (for review, see Caviston and Holzbaur, 2009), Milton/TRAK (van Spronsen et al., 2013), and JIP1 (Fu and Holzbaur, 2013).

Although the knock-down and dominant-negative experiments indicated that dynactin is required for the axonal transport of mitochondria, we wondered whether the CAP-Gly domain of p150 ${ }^{\text {Glued }}$ is required specifically for efficient initiation of mitochondrial transport from the distal axon, similar to the requirement for this domain in retrograde transport initiation of late endosomes/lysosomes. To answer this question, we treated DRG neurons with siRNA against $\mathrm{p} 150^{\text {Glued }}$ and rescued either with full-length wild-type $\mathrm{p} 150^{\text {Glued }}$ or with a construct that lacks the $N$-terminal CAP-Gly domain, $\Delta$ CAP-Gly (Fig. $5 E$ ). We measured retrograde flux of mitochondria from the distal axon and those along the mid-axon. Quantification of flux revealed a significant decrease in the number of cargos exiting the distal neurite after rescue with $\triangle$ CAP-Gly p150 Glued compared with rescue with wild-type p150 Glued (Fig. $5 F$ ). In contrast, there was no significant change in mitochondrial flux along the mid axon, indicating that the CAP-Gly domain is not required to sustain the active transport of this organelle. Despite the defect in transport initiation that we observed, we did not see long-term accumulation of mitochondria in the distal neurite. There was not a significant difference in mitochondrial density after rescue with either the wild-type or $\Delta$ CAP-Gly constructs of p150 ${ }^{\text {Glued. }} 7.1 \mu \mathrm{m}^{2} \pm 1.1$ for wild-type compared with $7.4 \mu \mathrm{m}^{2} \pm 2.4$ for $\Delta \mathrm{CAP}-\mathrm{Gly}$, data are shown as mean \pm SEM, which is consistent with our observations in late endosomes/lysosomes (Moughamian and Holzbaur, 2012).

We next focused on early endosomal motility. Rab5 is a marker of early endosomes and controls the initial steps of the endocytic pathway. Dynein associates with the Rab5 compartment and is necessary for proper trafficking through the early endosome system (Driskell et al., 2007). We investigated whether the CAP-Gly domain of dynactin is required for the efficient initiation of early endosome transport by depleting endogenous p150 ${ }^{\text {Glued }}$ and rescuing with either full-length or $\Delta$ CAP-Gly constructs of $\mathrm{p} 150$ Glued. We measured both distal and mid-axon flux after photobleaching (Fig. $1 E$ ) and found a significant decrease in distal flux after rescue with $\triangle$ CAP-Gly compared with rescue with wild-type p150 Glued (Fig. 6A,B). However, we did not observe a difference in mid-axon flux (Fig. 6A, C), which reveals that the CAP-Gly domain is required for proper early endosome transport only from the distal axon.

Signaling endosomes are a specific endosome population that transport activated neurotrophin receptor complexes to the cell soma and are critical for long-term neuronal survival. The motility of signaling endosomes is mediated by dynein (Delcroix et al., 2003; Heerssen et al., 2004; Deinhardt et al., 2006). We performed
A

Rab5-early endosomes

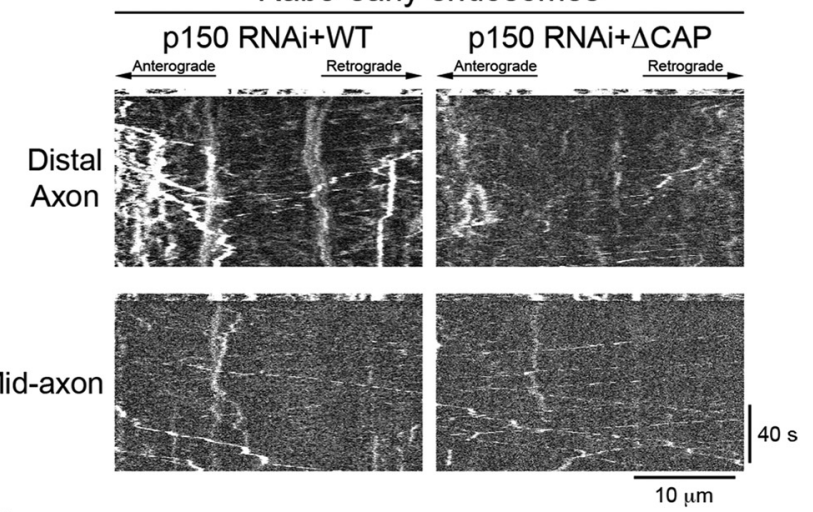

B
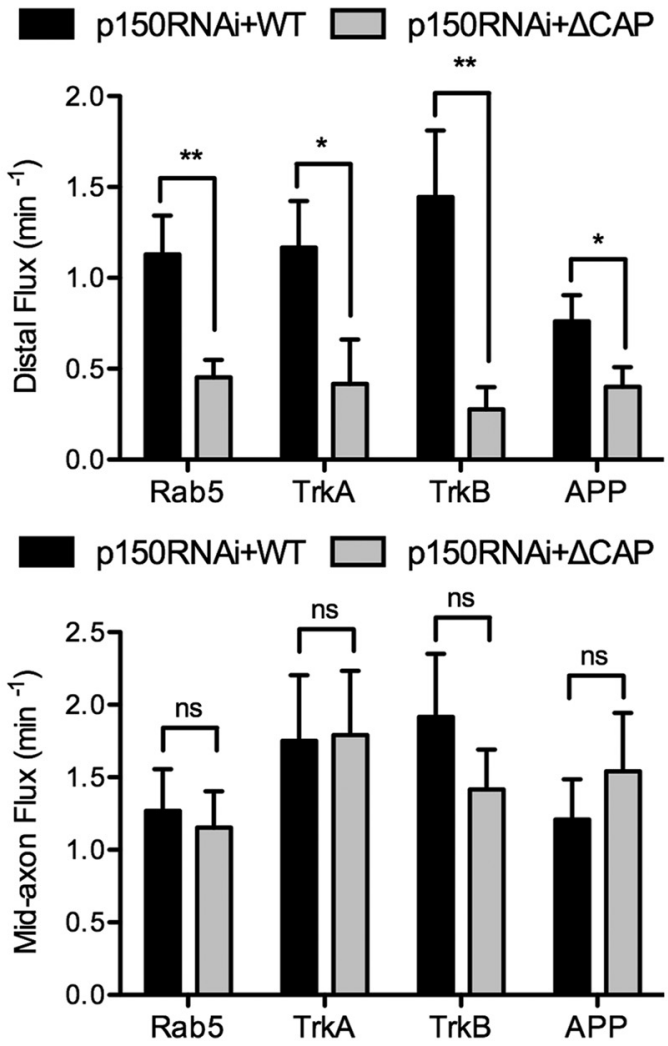

Figure 6. Dynactin promotes the efficient initiation of transport for multiple cargo types. A, Kymographs of Rab5 motility in DRG neurons imaged at 4 DIV after siRNA knock-down of p 150 Glued and rescue with either full-length wild-type $p 150^{\text {Glued }}$ or $\Delta$ CAP-Gly $p 150^{\text {Glued. }}$. For distal flux, a zone 10 $\mu \mathrm{m}$ proximal to theneuriteend was photobleached; for mid-axon flux, azone $>100 \mu$ m proximal to the neurite end was photobleached, as described in Figure 1E. Entry of cargos into the bleach zone was assessed with time-lapse imaging. Kymographs are of the photobleached zone before and after photobleaching. Scale bars, $10 \mu \mathrm{m}$ and $40 \mathrm{~s}$ for the $x$ and $y$ axes, respectively. B, Quantification of the retrograde flux from the distal axon for Rab5 early endosomes, TrkA- and TrkB-signaling endosomes, and APP vesicles after siRNA knock-down of $p 150^{\text {Glued }}$ and rescue with either full-length wild-type $\mathrm{p} 150^{\text {Glued }}$ or $\triangle$ CAP-Gly $\mathrm{p} 150^{\text {Glued }}$. Flux was determined by counting the number of retrograde vesicles that moved $>3.5 \mu$ m into the photobleached zone. Data are shown as mean \pm SEM; $n=9-25$ neurites per condition. C, Quantification of mid-axon retrograde flux for Rab5 early endosomes, TrkAand TrkB-signaling endosomes, and APP vesicles after siRNA knock-down of p150 ${ }^{\text {Glued }}$ and rescue with either full-length wild-type $150^{\text {Glued }}$ or $\triangle$ CAP-Gly $150^{\text {Glued. }}$. Flux was determined as in B. Data are shown as mean \pm SEM; $n=12-13$ neurites per condition; ${ }^{* *} p<0.01,{ }^{*} p<0.05$, ns: not significant $p>0.05$, Student's $t$ test.

the photobleaching assay to measure the flux of two markers of signaling endosomes, TrkA and TrkB, after knock-down of endogenous p $150^{\text {Glued }}$ and rescue with either wild-type p150 Glued or $\Delta$ CAP-Gly p 150 Glued . Our experiments were performed in the 
absence of added neurotrophins to measure the constitutive axonal transport of the TrkA-positive and TrkB-positive compartments. We observed a decrease in the distal flux after rescue with $\Delta$ CAP-Gly p $150^{\text {Glued }}$ compared with rescue with wild-type, but observed no effect on the mid-axon flux (Fig. 6B, C).

Finally, we examined the transport of APP, which is primarily an anterograde-directed cargo driven by the kinesin-1 motor (Kamal et al., 2000). However, dynein is also bound to APP vesicles and is required for retrograde APP motility (Reis et al.,

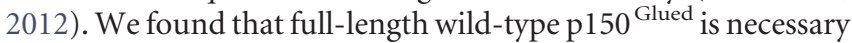
for the initiation of APP transport from the distal axon but not from the mid-axon (Fig. $6 B, C$ ). Similar to our observations on both lysosomes and mitochondria, we observed no significant accumulation of Rab5, TrkA, TrkB, or APP in the distal axon after knock-down of $150^{\text {Glued }}$ and rescue with either wild-type or $\Delta$ CAP-Gly p $150^{\text {Glued }}$ constructs. These data show that the CAPGly domain of dynactin, in concert with the +TIPs, promotes the efficient initiation of retrograde transport, specifically from the distal axon for numerous cargos, and suggests this is a highly conserved mechanism for cargo transport from the distal axon.

\section{Discussion}

Axonal transport is critical for neuronal homeostasis and survival. Kinesin motors drive cargo movement from soma into the axon initial segment and then along the axonal process (Hirokawa et al., 2009). Dynein is the sole retrograde motor in axons, so it is not surprising that mutations in dynein or the dynein activator dynactin result in a spectrum of neurodevelopmental and neurodegenerative disorders (Perlson et al., 2010). Recent studies on one set of mutations in dynactin that cause Perry syndrome (Farrer et al., 2009) identified the CAP-Gly domain of the p150 Glued subunit as essential for the efficient initiation of retrograde transport (Lloyd et al., 2012; Moughamian and Holzbaur, 2012). Here, we extend our understanding into the mechanisms by which dynein-mediated retrograde transport is initiated. We have shown that dynamic microtubules are enriched in an $\sim 10$ $\mu \mathrm{m}$ zone at the distal end of the axon, coincident with the zone of dynactin enrichment identified previously (Moughamian and Holzbaur, 2012). The end-binding proteins EB1 and EB3 are recruited to these dynamic microtubules and are required for the efficient initiation of transport from the distal axon. Similar to previous observations on the role of the CAP-Gly domain, we found that depletion of EBs from neurons had no effect on transport along the mid-axon, indicating that there is a unique mechanism for transport initiation distally that is not required to initiate or maintain the motility of cargo transported along the mid-axon.

We have also now established a necessary role for CLIP-170 in transport initiation from the distal axon. Although EBs have been shown to bind directly to the CAP-Gly domain of dynactin, this interaction is not sufficient to recruit dynactin to dynamic microtubule plus-ends. Instead, EBs recruit CLIP-170, which in turn recruits dynactin, in an ordered recruitment model for the initiation of retrograde transport from the distal axon (Fig. 7). At the neurite tip, there is an increase in dynamic microtubules that are decorated with EBs. CLIP-170 binds to these EB-decorated dynamic microtubule ends, and in turn recruits dynactin. The direct binding of dynein to dynactin may then facilitate formation of a motile motor-cargo complex allowing for efficient transport initiation.

The observations reported here for primary neurons can be compared with previous observations in non-neuronal cells. In both Drosophila S2 cells and mammalian HeLa cells, there is no apparent requirement for a plus-end initiation complex (Kim et al., 2007; Dixit et al., 2008). However, during the regulated trafficking of melanosomes in Xenopus melanophores, both dynamic microtubules and CLIP-170 are required for the rapid redistribution of these organelles from the cell periphery to the cell center (Lomakin et al., 2009), which is consistent with a role for + TIPs in facilitating transport. Therefore, the mechanism for the distal axon described in Figure 7 may only be required for high-flux trafficking events or for trafficking in regions of the cell with elevated microtubule dynamicity.

Perry-syndrome-associated mutations in dynactin completely abrogate localization of dynactin to the distal neurite, yet do not cause clinically significant neurodegeneration until the fifth or sixth decade of life (Farrer et al., 2009). It may be that in healthy neurons, highly efficient axonal transport is not required, but because aging slows transport overall, this mechanism becomes more important. Consistent with this interpretation, knock-out of CLIP-170 in the mouse resulted in only a mild phenotype; mice are viable but display fertility defects (Akhmanova et al., 2005). However, it is possible that analysis of aging knock-out mice might reveal a specific transport deficit. Alternatively, structurally related proteins such as CLIP-115 may compensate for the loss of CLIP-170 in vivo.

The observations described here indicate that EBs play a critical role in transport in neurons. EBs function at the core of a protein-protein interaction network that recruits proteins including CLIP-170 and dynactin to the plus-end of the microtubule (Akhmanova and Steinmetz, 2008). Therefore, EBs are a key mediator in the recruitment of proteins that facilitate transport initiation onto dynamic microtubules. Although both CLIP-170 and p $150^{\text {Glued }}$ contain CAP-Gly domains that mediate their binding to EBs in solution, we have shown here that EBs are not sufficient to recruit dynactin to the microtubule plus-end. Interestingly, the $\beta 2-\beta 3$ loops of the CAP-Gly domains of CLIP-170 and $\mathrm{p} 150^{\text {Glued }}$ are distinct (Bjelić et al., 2012). The $\beta 2-\beta 3$ loop interacts with EBs and this difference may underlie our observations. The result suggests that EBs cannot simultaneously bind microtubules and dynactin, and therefore EBs and dynactin cannot be co-recruited onto the microtubule. The mediator between EBs and dynactin is CLIP-170, which can exist in an autoinhibited state. The binding of CLIP-170 to EBs is highly regulated by phosphorylation (Lansbergen et al., 2004; Lee et al., 2010); therefore, the phosphorylation of CLIP-170 may be the trigger that initiates transport from the distal axon. This is an attractive regulatory mechanism because it would allow the distal axon precise temporal control of transport initiation.

The plus-end tracking protein Lis1 also has an important role in transport initiation. Studies on endosomal motility in fungi first implicated Lis1 as an initiator of retrograde transport in filamentous fungi; interestingly, these studies found rapid dissociation for fluorescently labeled Lis1 from the motile dyneincargo complex (Lenz et al., 2006; Egan et al., 2012). Our studies in primary mammalian neurons support the hypothesis that Lis 1 is required for axonal transport, as suggested by the work of Pandey and Smith (2011). Further, our work shows that Lis 1 is constitutively required for transport initiation throughout the neuron, both from the distal axon and along the mid-axon. Therefore, in mammalian neurons, Lis1 functions distinctly from the EB/ CLIP-170/dynactin pathway in the initiation of dynein-mediated transport. The requirement for Lis1 in the initiation of dyneindriven motility throughout the axon suggests that Lis 1 is acting at the level of the dynein motor (Fig. 7). Lis1 enhances dynein's microtubule affinity, inducing a persistent attachment and high 


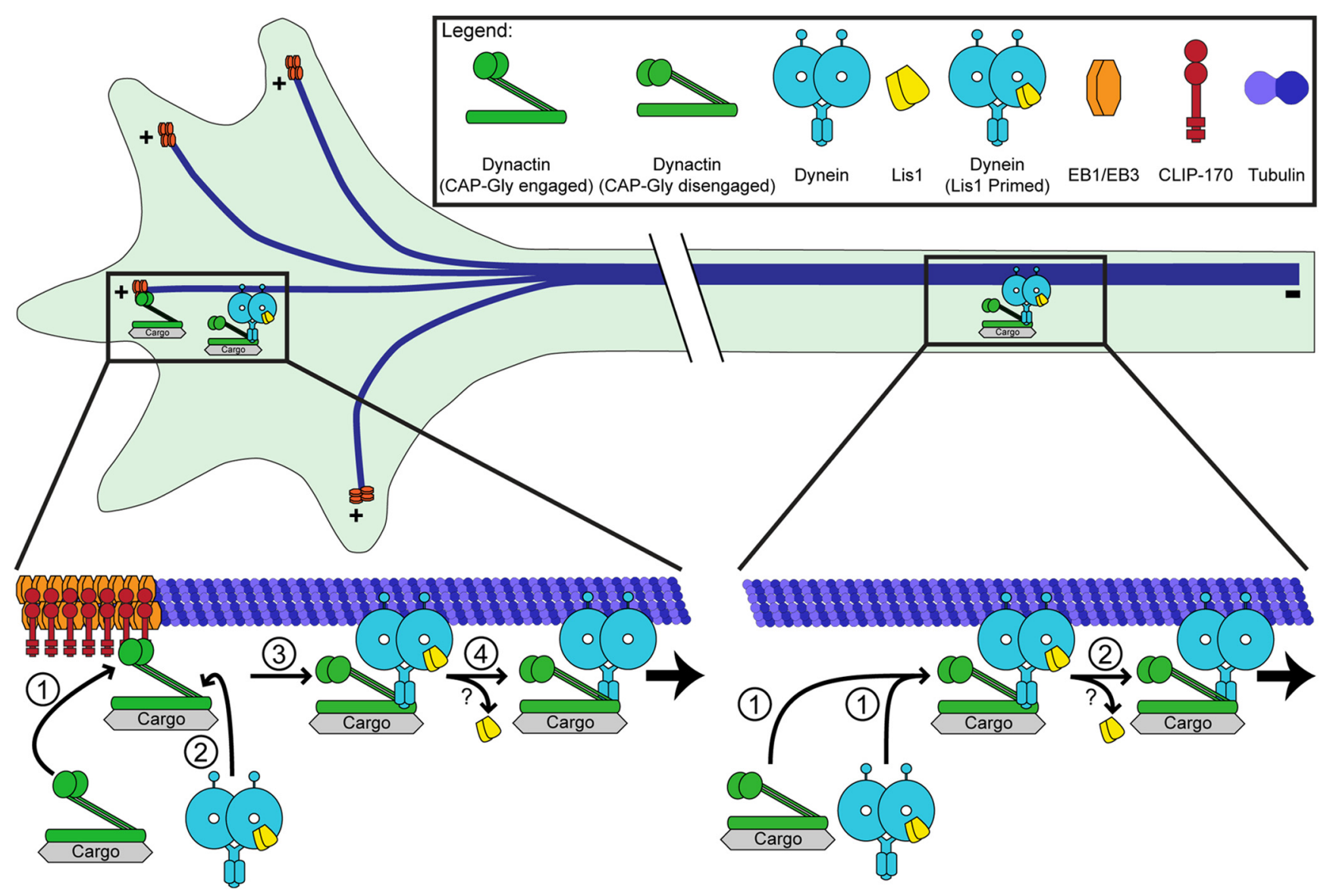

Figure 7. Model for the initiation of dynein-mediated retrograde transport in neurons. We propose two synergistic pathways for retrograde transport initiation in the neuron: the EB/CLIP-170/ dynactin pathway and the Lis1 pathway. The EB/CLIP-170/dynactin pathway is necessary only in the distal axon, likely due to the locally high concentration of dynamic microtubule plus-ends. The dynamically growing plus-ends recruit EBs, which in turn recruit CLIP-170. The CAP-Gly domain of p $150^{\text {Glued }}$ then binds to CLIP-170, thereby recruiting the dynactin complex onto the microtubule plus-end. Subsequently, Lis1-primed dynein binds to dynactin and this binding may lead to the disengagement of CAP-Gly domain from the + TIP complex. Lis1 is likely released and then retrograde transport is initiated. Lis1 release from the motile dynein complex has been observed in filamentous fungi (Lenz et al., 2006; Egan et al., 2012), but not yet in mammalian neurons. In the mid-axon, the microtubule cytoskeleton is less dynamic, so the EB/CLIP-170/dynactin pathway is not required. Lis1-primed dynein is recruited to the microtubule. Once dynein and dynactin bind, Lis1 is released and retrograde transport initiates.

force state (Yamada et al., 2008; McKenney et al., 2010; Huang et al., 2012). This state has been proposed to be critical in driving the motility of larger $(>1 \mu \mathrm{m})$ cargos along the axon (Yi et al., 2011). However, here we imaged a population of late endosomes and lysosomes with an average size of $90 \mathrm{~nm}$ and found that Lis1 was required for efficient motility of smaller cargo as well. Therefore, our data support a more general model for Lis 1 function in which this binding partner enhances transport initiation by acting directly on dynein, priming the motor for stronger attachment onto the microtubule, a mechanism distinct from the CAP-Glydependent mechanism operating at the distal neurite.

The two distinct pathways proposed in Figure 7 likely function synergistically to promote efficient retrograde transport. The EB/CLIP-170/dynactin pathway acts on the microtubule tracks. The distal axon is enriched with dynamic microtubules, so the EB/CLIP-170/dynactin pathway acts at the level of the microtubule cytoskeleton to efficiently capture the microtubule track and recruit the motile dynein motor complex. In contrast, microtubules in the mid-axon are less dynamic, so the EB/CLIP-170/ dynactin pathway, which captures dynamic microtubules, is not essential. In contrast, the Lis1 pathway acts directly on the dynein motor and is therefore necessary for both constitutive axonal transport and transport initiation throughout the axon. These pathways are not mutually exclusive and likely function together in the distal axon to efficiently initiate transport. The EB/CLIP170/dynactin pathway first recruits dynein onto the dynamic microtubule cytoskeleton and then Lis1 primes dynein for motility. In the mid-axon, where the microtubule cytoskeleton is less dynamic, only the Lis1 pathway is necessary for efficient transport initiation.

The mechanism described here for transport initiation is likely to be highly conserved, because studies in Drosophila have shown that a mutation in the CAP-Gly domain leads to the distal accumulation of organelles in neurons (Lloyd et al., 2012). Further, we now show that this mechanism is broadly used for a range of neuronal cargos. Here we show that the CAP-Gly domain of dynactin is required for the efficient initiation of transport of multiple cargo types, including early and late endosomes, mitochondria, and TrkA-, Trk-B-, and APP-positive organelles. These different cargos undergo very different types of motility along the axon, ranging from the highly processive motility of the APP compartment (Kaether et al., 2000) to the highly saltatory motility of late endosomes and lysosomes and mitochondria (Hendricks et al., 2010; Maday et al., 2012; Saxton and Hollenbeck, 2012). However, we found that regardless of the cargo's motility behavior, bidirectional, retrograde biased, or anterograde biased, the CAP-Gly domain of dynactin regulates the initiation of their transport from the distal axon. Future work will be 
required to more fully explore the nature of the initiation zone found at the distal end of neurons both in vitro and in vivo (Lloyd et al., 2012; Moughamian and Holzbaur, 2012) that selectively recruits and retains + TIPS such as EBs and dynactin required for this mechanism.

\section{References}

Akhmanova A, Steinmetz MO (2008) Tracking the ends: a dynamic protein network controls the fate of microtubule tips. Nat Rev Mol Cell Biol 9:309-322. CrossRef Medline

Akhmanova A, Mausset-Bonnefont AL, van Cappellen W, Keijzer N, Hoogenraad CC, Stepanova T, Drabek K, van der Wees J, Mommaas M, Onderwater J, van der Meulen H, Tanenbaum ME, Medema RH, Hoogerbrugge J, Vreeburg J, Uringa EJ, Grootegoed JA, Grosveld F, Galjart N (2005) The microtubule plus-end-tracking protein CLIP-170 associates with the spermatid manchette and is essential for spermatogenesis. Genes and development 19:2501-2515. CrossRef Medline

Askham JM, Vaughan KT, Goodson HV, Morrison EE (2002) Evidence that an interaction between EB1 and p150(Glued) is required for the formation and maintenance of a radial microtubule array anchored at the centrosome. Mol Biol Cell 13:3627-3645. CrossRef Medline

Berrueta L, Tirnauer JS, Schuyler SC, Pellman D, Bierer BE (1999) The APC-associated protein EB1 associates with components of the dynactin complex and cytoplasmic dynein intermediate chain. Curr Biol 9:425428. Medline

Bieling P, Laan L, Schek H, Munteanu EL, Sandblad L, Dogterom M, Brunner D, Surrey T (2007) Reconstitution of a microtubule plus-end tracking system in vitro. Nature 450:1100-1105. CrossRef Medline

Bieling P, Kandels-Lewis S, Telley IA, van Dijk J, Janke C, Surrey T (2008) CLIP-170 tracks growing microtubule ends by dynamically recognizing composite EB1/tubulin-binding sites. J Cell Biol 183:1223-1233. CrossRef Medline

Bjelić S, De Groot CO, Schärer MA, Jaussi R, Bargsten K, Salzmann M, Frey D, Capitani G, Kammerer RA, Steinmetz MO (2012) Interaction of mammalian end binding proteins with CAP-Gly domains of CLIP-170 and p150(glued). J Struct Biol 177:160-167. CrossRef Medline

Brouhard GJ, Stear JH, Noetzel TL, Al-Bassam J, Kinoshita K, Harrison SC, Howard J, Hyman AA (2008) XMAP215 is a processive microtubule polymerase. Cell 132:79-88. CrossRef Medline

Castoldi M, Popov AV (2003) Purification of brain tubulin through two cycles of polymerization-depolymerization in a high-molarity buffer. Protein Expr Purif 32:83-88. CrossRef Medline

Caviston JP, Holzbaur EL (2009) Huntingtin as an essential integrator of intracellular vesicular trafficking. Trends Cell Biol 19:147-155. CrossRef Medline

Caviston JP, Zajac AL, Tokito M, Holzbaur EL (2011) Huntingtin coordinates the dynein-mediated dynamic positioning of endosomes and lysosomes. Mol Biol Cell 22:478-492. CrossRef Medline

Deinhardt K, Salinas S, Verastegui C, Watson R, Worth D, Hanrahan S, Bucci C, Schiavo G (2006) Rab5 and Rab7 control endocytic sorting along the axonal retrograde transport pathway. Neuron 52:293-305. CrossRef Medline

Delcroix JD, Valletta JS, Wu C, Hunt SJ, Kowal AS, Mobley WC (2003) NGF signaling in sensory neurons: evidence that early endosomes carry NGF retrograde signals. Neuron 39:69-84. CrossRef Medline

Dixit R, Levy JR, Tokito M, Ligon LA, Holzbaur EL (2008) Regulation of dynactin through the differential expression of p150Glued isoforms. J Biol Chem 283:33611-33619. CrossRef Medline

Dixit R, Barnett B, Lazarus JE, Tokito M, Goldman YE, Holzbaur EL (2009) Microtubule plus-end tracking by CLIP-170 requires EB1. Proc Natl Acad Sci U S A 106:492-497. CrossRef Medline

Driskell OJ, Mironov A, Allan VJ, Woodman PG (2007) Dynein is required for receptor sorting and the morphogenesis of early endosomes. Nat Cell Biol 9:113-120. CrossRef Medline

Dujardin DL, Barnhart LE, Stehman SA, Gomes ER, Gundersen GG, Vallee RB (2003) A role for cytoplasmic dynein and LIS1 in directed cell movement. J Cell Biol 163:1205-1211. CrossRef Medline

Egan MJ, Tan K, Reck-Peterson SL (2012) Lis1 is an initiation factor for dynein-driven organelle transport. J Cell Biol 197:971-982. CrossRef Medline

Farrer MJ, Hulihan MM, Kachergus JM, Dächsel JC, Stoessl AJ, Grantier LL, Calne S, Calne DB, Lechevalier B, Chapon F, Tsuboi Y, Yamada T, Gut- mann L, Elibol B, Bhatia KP, Wider C, Vilariño-Güell C, Ross OA, Brown LA, Castanedes-Casey M, et al. (2009) DCTN1 mutations in Perry syndrome. Nat Genet 41:163-165. CrossRef Medline

Fu MM, Holzbaur ELF (2013) JIP1 regulates the directionality of APP axonal transport by coordinating kinesin and dynein motors. J Cell Biol., in press.

He Y, Francis F, Myers KA, Yu W, Black MM, Baas PW (2005) Role of cytoplasmic dynein in the axonal transport of microtubules and neurofilaments. J Cell Biol 168:697-703. CrossRef Medline

Heerssen HM, Pazyra MF, Segal RA (2004) Dynein motors transport activated Trks to promote survival of target-dependent neurons. Nat Neurosci 7:596-604. CrossRef Medline

Hendricks AG, Perlson E, Ross JL, Schroeder HW 3rd, Tokito M, Holzbaur EL (2010) Motor coordination via a tug-of-war mechanism drives bidirectional vesicle transport. Curr Biol 20:697-702. CrossRef Medline

Hirokawa N, Noda Y, Tanaka Y, Niwa S (2009) Kinesin superfamily motor proteins and intracellular transport. Nat Rev Mol Cell Biol 10:682-696. CrossRef Medline

Holleran EA, Tokito MK, Karki S, Holzbaur EL (1996) Centractin (ARP1) associates with spectrin revealing a potential mechanism to link dynactin to intracellular organelles. J Cell Biol 135:1815-1829. CrossRef Medline

Honnappa S, Okhrimenko O, Jaussi R, Jawhari H, Jelesarov I, Winkler FK, Steinmetz MO (2006) Key interaction modes of dynamic + TIP networks. Molecular Cell 23:663-671. CrossRef Medline

Honnappa S, Gouveia SM, Weisbrich A, Damberger FF, Bhavesh NS, Jawhari H, Grigoriev I, van Rijssel FJ, Buey RM, Lawera A, Jelesarov I, Winkler FK, Wüthrich K, Akhmanova A, Steinmetz MO (2009) An EB1-binding motif acts as a microtubule tip localization signal. Cell 138:366-376. CrossRef Medline

Huang J, Roberts AJ, Leschziner AE, Reck-Peterson SL (2012) Lis1 Acts as a "Clutch" between the ATPase and Microtubule-Binding Domains of the Dynein Motor. Cell 150:975-986. CrossRef Medline

Kaether C, Skehel P, Dotti CG (2000) Axonal membrane proteins are transported in distinct carriers: a two-color video microscopy study in cultured hippocampal neurons. Mol Biol Cell 11:1213-1224. Medline

Kamal A, Stokin GB, Yang Z, Xia CH, Goldstein LS (2000) Axonal transport of amyloid precursor protein is mediated by direct binding to the kinesin light chain subunit of kinesin-I. Neuron 28:449-459. CrossRef Medline

Kapitein LC, Yau KW, Hoogenraad CC (2010) Microtubule dynamics in dendritic spines. Methods Cell Biol 97:111-132. CrossRef Medline

Kardon JR, Vale RD (2009) Regulators of the cytoplasmic dynein motor. Nat Rev Mol Cell Biol 10:854-865. CrossRef Medline

Kardon JR, Reck-Peterson SL, Vale RD (2009) Regulation of the processivity and intracellular localization of Saccharomyces cerevisiae dynein by dynactin. Proc Natl Acad Sci U S A 106:5669-5674. CrossRef Medline

Kim H, Ling SC, Rogers GC, Kural C, Selvin PR, Rogers SL, Gelfand VI (2007) Microtubule binding by dynactin is required for microtubule organization but not cargo transport. J Cell Biol 176:641-651. CrossRef Medline

King SJ, Schroer TA (2000) Dynactin increases the processivity of the cytoplasmic dynein motor. Nat Cell Biol 2:20-24. CrossRef Medline

Kiyomitsu T, Cheeseman IM (2012) Chromosome- and spindle-polederived signals generate an intrinsic code for spindle position and orientation. Nat Cell Biol 14:311-317. CrossRef Medline

Komarova Y, De Groot CO, Grigoriev I, Gouveia SM, Munteanu EL, Schober JM, Honnappa S, Buey RM, Hoogenraad CC, Dogterom M, Borisy GG, Steinmetz MO, Akhmanova A (2009) Mammalian end binding proteins control persistent microtubule growth. J Cell Biol 184:691-706. CrossRef Medline

Lansbergen G, Komarova Y, Modesti M, Wyman C, Hoogenraad CC, Goodson HV, Lemaitre RP, Drechsel DN, van Munster E, Gadella TW Jr, Grosveld F, Galjart N, Borisy GG, Akhmanova A (2004) Conformational changes in CLIP-170 regulate its binding to microtubules and dynactin localization. J Cell Biol 166:1003-1014. CrossRef Medline

Lazarus JE, Moughamian AJ, Tokito MK, Holzbaur ELF (2013) Dynactin subunit p150Glued is a neuron-specific anti-catastrophe factor. PLOS Biology, in press.

Lee HS, Komarova YA, Nadezhdina ES, Anjum R, Peloquin JG, Schober JM, Danciu O, van Haren J, Galjart N, Gygi SP, Akhmanova A, Borisy GG (2010) Phosphorylation controls autoinhibition of cytoplasmic linker protein-170. Mol Biol Cell 21:2661-2673. CrossRef Medline

Lenz JH, Schuchardt I, Straube A, Steinberg G (2006) A dynein loading zone 
for retrograde endosome motility at microtubule plus-ends. EMBO J 25: 2275-2286. CrossRef Medline

Levy JR, Holzbaur EL (2008) Dynein drives nuclear rotation during forward progression of motile fibroblasts. J Cell Sci 121:3187-3195. CrossRef Medline

Li S, Finley J, Liu ZJ, Qiu SH, Chen H, Luan CH, Carson M, Tsao J, Johnson D, Lin G, Zhao J, Thomas W, Nagy LA, Sha B, DeLucas LJ, Wang BC, Luo M (2002) Crystal structure of the cytoskeleton-associated protein glycine-rich (CAP-Gly) domain. J Biol Chem 277:48596-48601. CrossRef Medline

Ligon LA, Shelly SS, Tokito M, Holzbaur EL (2003) The microtubule plusend proteins EB1 and dynactin have differential effects on microtubule polymerization. Mol Biol Cell 14:1405-1417. CrossRef Medline

Liu Z, Steward R, Luo L (2000) Drosophila Lis1 is required for neuroblast proliferation, dendritic elaboration and axonal transport. Nat Cell Biol 2:776-783. CrossRef Medline

Lloyd TE, Machamer J, O’Hara K, Kim JH, Collins SE, Wong MY, Sahin B, Imlach W, Yang Y, Levitan ES, McCabe BD, Kolodkin AL (2012) The p150(Glued) CAP-Gly domain regulates initiation of retrograde transport at synaptic termini. Neuron 74:344-360. CrossRef Medline

Lomakin AJ, Semenova I, Zaliapin I, Kraikivski P, Nadezhdina E, Slepchenko BM, Akhmanova A, Rodionov V (2009) CLIP-170-dependent capture of membrane organelles by microtubules initiates minus-end directed transport. Dev Cell 17:323-333. CrossRef Medline

Maday S, Wallace KE, Holzbaur EL (2012) Autophagosomes initiate distally and mature during transport toward the cell soma in primary neurons. J Cell Biol 196:407-417. CrossRef Medline

Martin M, Iyadurai SJ, Gassman A, Gindhart JG Jr, Hays TS, Saxton WM (1999) Cytoplasmic dynein, the dynactin complex, and kinesin are interdependent and essential for fast axonal transport. Mol Biol Cell 10:3717-3728. Medline

Maurer SP, Fourniol FJ, Bohner G, Moores CA, Surrey T (2012) EBs recognize a nucleotide-dependent structural cap at growing microtubule ends. Cell 149:371-382. CrossRef Medline

McKenney RJ, Vershinin M, Kunwar A, Vallee RB, Gross SP (2010) LIS1 and NudE induce a persistent dynein force-producing state. Cell 141: 304-314. CrossRef Medline

Mishima M, Maesaki R, Kasa M, Watanabe T, Fukata M, Kaibuchi K, Hakoshima T (2007) Structural basis for tubulin recognition by cytoplasmic linker protein 170 and its autoinhibition. Proc Natl Acad Sci U S A 104: 10346-10351. CrossRef Medline

Moughamian AJ, Holzbaur EL (2012) Dynactin is required for transport initiation from the distal axon. Neuron 74:331-343. CrossRef Medline

Pandey JP, Smith DS (2011) A Cdk5-dependent switch regulates Lis1/ Ndel1/dynein-driven organelle transport in adult axons. J Neurosci 31: 17207-17219. CrossRef Medline

Perlson E, Maday S, Fu MM, Moughamian AJ, Holzbaur EL (2010) Retrograde axonal transport: pathways to cell death? Trends Neurosci 33:335-344. CrossRef Medline

Pierre P, Scheel J, Rickard JE, Kreis TE (1992) CLIP-170 links endocytic vesicles to microtubules. Cell 70:887-900. CrossRef Medline

Pilling AD, Horiuchi D, Lively CM, Saxton WM (2006) Kinesin-1 and Dynein are the primary motors for fast transport of mitochondria in Drosophila motor axons. Mol Biol Cell 17:2057-2068. CrossRef Medline

Quintyne NJ, Gill SR, Eckley DM, Crego CL, Compton DA, Schroer TA (1999) Dynactin is required for microtubule anchoring at centrosomes. J Cell Biol 147:321-334. CrossRef Medline

Reis GF, Yang G, Szpankowski L, Weaver C, Shah SB, Robinson JT, Hays TS, Danuser G, Goldstein LS (2012) Molecular motor function in axonal transport in vivo probed by genetic and computational analysis in Drosophila. Mol Biol Cell 23:1700-1714. CrossRef Medline

Ross JL, Wallace K, Shuman H, Goldman YE, Holzbaur EL (2006) Processive bidirectional motion of dynein-dynactin complexes in vitro. Nat Cell Biol 8:562-570. CrossRef Medline

Saxton WM, Hollenbeck PJ (2012) The axonal transport of mitochondria. J Cell Sci 125:2095-2104. CrossRef Medline

Schroer TA (2004) Dynactin. Annu Rev Cell Dev Biol 20:759-779. CrossRef Medline

Schuster M, Kilaru S, Ashwin P, Lin C, Severs NJ, Steinberg G (2011) Controlled and stochastic retention concentrates dynein at microtubule ends to keep endosomes on track. EMBO J 30:652-664. CrossRef Medline
Schuyler SC, Pellman D (2001) Microtubule "plus-end-tracking proteins": The end is just the beginning. Cell 105:421-424. CrossRef Medline

Stepanova T, Slemmer J, Hoogenraad CC, Lansbergen G, Dortland B, De Zeeuw CI, Grosveld F, van Cappellen G, Akhmanova A, Galjart N (2003) Visualization of microtubule growth in cultured neurons via the use of EB3-GFP (end-binding protein 3-green fluorescent protein). J Neurosci 23:2655-2664. Medline

Stepanova T, Smal I, van Haren J, Akinci U, Liu Z, Miedema M, Limpens R, van Ham M, van der Reijden M, Poot R, Grosveld F, Mommaas M, Meijering E, Galjart N (2010) History-dependent catastrophes regulate axonal microtubule behavior. Curr Biol 20:1023-1028. CrossRef Medline

Trybus KM, Freyzon Y, Faust LZ, Sweeney HL (1997) Spare the rod, spoil the regulation: necessity for a myosin rod. Proc Natl Acad Sci U S A 94:48-52. CrossRef Medline

Tsai JW, Bremner KH, Vallee RB (2007) Dual subcellular roles for LIS1 and dynein in radial neuronal migration in live brain tissue. Nat Neurosci 10:970-979. CrossRef Medline

Valetti C, Wetzel DM, Schrader M, Hasbani MJ, Gill SR, Kreis TE, Schroer TA (1999) Role of dynactin in endocytic traffic: effects of dynamitin overexpression and colocalization with CLIP-170. Mol Biol Cell 10:4107-4120. Medline

van Haren J, Draegestein K, Keijzer N, Abrahams JP, Grosveld F, Peeters PJ, Moechars D, Galjart N (2009) Mammalian Navigators are microtubule plus-end tracking proteins that can reorganize the cytoskeleton to induce neurite-like extensions. Cell Motil Cytoskeleton 66:824-838. CrossRef Medline

van Spronsen M, Mikhaylova M, Lipka J, Schlager MA, van den Heuvel DJ, Kuijpers M, Wulf PS, Keijzer N, Demmers J, Kapitein LC, Jaarsma D, Gerritsen HC, Akhmanova A, Hoogenraad CC (2013) TRAK/Milton Motor-Adaptor Proteins Steer Mitochondrial Trafficking to Axons and Dendrites. Neuron 77:485-502. CrossRef Medline

Vaughan KT, Tynan SH, Faulkner NE, Echeverri CJ, Vallee RB (1999) Colocalization of cytoplasmic dynein with dynactin and CLIP-170 at microtubule distal ends. J Cell Sci 112:1437-1447. Medline

Vaughan PS, Miura P, Henderson M, Byrne B, Vaughan KT (2002) A role for regulated binding of p150(Glued) to microtubule plus ends in organelle transport. J Cell Biol 158:305-319. CrossRef Medline

Waterman-Storer CM, Karki SB, Kuznetsov SA, Tabb JS, Weiss DG, Langford GM, Holzbaur EL (1997) The interaction between cytoplasmic dynein and dynactin is required for fast axonal transport. Proc Natl Acad Sci U S A 94:12180-12185. CrossRef Medline

Watson P, Stephens DJ (2006) Microtubule plus-end loading of p150(Glued) is mediated by EB1 and CLIP-170 but is not required for intracellular membrane traffic in mammalian cells. J Cell Sci 119:2758-2767. CrossRef Medline

Watson P, Forster R, Palmer KJ, Pepperkok R, Stephens DJ (2005) Coupling of ER exit to microtubules through direct interaction of COPII with dynactin. Nat Cell Biol 7:48-55. CrossRef Medline

Weisbrich A, Honnappa S, Jaussi R, Okhrimenko O, Frey D, Jelesarov I, Akhmanova A, Steinmetz MO (2007) Structure-function relationship of CAP-Gly domains. Nat Struct Mol Biol 14:959-967. CrossRef Medline

Xiang X, Osmani AH, Osmani SA, Xin M, Morris NR (1995) NudF, a nuclear migration gene in Aspergillus nidulans, is similar to the human LIS-1 gene required for neuronal migration. Mol Biol Cell 6:297-310. CrossRef Medline

Yamada M, Toba S, Yoshida Y, Haratani K, Mori D, Yano Y, Mimori-Kiyosue Y, Nakamura T, Itoh K, Fushiki S, Setou M, Wynshaw-Boris A, Torisawa T, Toyoshima YY, Hirotsune S (2008) LIS1 and NDEL1 coordinate the plusend-directed transport of cytoplasmic dynein. EMBO J 27:2471-2483. CrossRef Medline

Yi JY, Ori-McKenney KM, McKenney RJ, Vershinin M, Gross SP, Vallee RB (2011) High-resolution imaging reveals indirect coordination of opposite motors and a role for LIS1 in high-load axonal transport. J Cell Biol 195:193-201. CrossRef Medline

Zhang J, Li S, Fischer R, Xiang X (2003) Accumulation of cytoplasmic dynein and dynactin at microtubule plus ends in Aspergillus nidulans is kinesin dependent. Mol Biol Cell 14:1479-1488. CrossRef Medline

Zhang J, Yao X, Fischer L, Abenza JF, Peñalva MA, Xiang X (2011) The p25 subunit of the dynactin complex is required for dynein-early endosome interaction. J Cell Biol 193:1245-1255. CrossRef Medline 